\title{
TLR4 signaling in the development of colitis-associated cancer and its possible interplay with microRNA-155
}

Jie Guo ${ }^{1,2}$, Mengfan Liao ${ }^{1,2}$ and Jun Wang ${ }^{1,2^{*}}$ (D)

\begin{abstract}
Ulcerative colitis (UC) has closely been associated with an increased risk of colorectal cancer. However, the exact mechanisms underlying colitis-associated cancer (CAC) development remain unclear. As a classic pattern-recognition receptor, Toll like receptor (TLR)4 is a canonical receptor for lipopolysaccharide of Gram-negative bacteria (including two CAC-associated pathogens Fusobacterium nucleatum and Salmonella), and functions as a key bridge molecule linking oncogenic infection to colonic inflammatory and malignant processes. Accumulating studies verified the overexpression of TLR4 in colitis and CAC, and the over-expressed TLR4 might promote colitis-associated tumorigenesis via facilitating cell proliferation, protecting malignant cells against apoptosis, accelerating invasion and metastasis, as well as contributing to the creation of tumor-favouring cellular microenvironment. In recent years, considerable attention has been focused on the regulation of TLR4 signaling in the context of colitis-associated tumorigenesis. MicroRNA (miR)-155 and TLR4 exhibited a similar dynamic expression change during CAC development and shared similar CAC-promoting properties. The available data demonstrated an interplay between TLR4 and miR-155 in the context of different disorders or cell lines. miR-155 could augment TLR4 signaling through targeting negative regulators SOCS1 and SHIP1; and TLR4 activation would induce miR-155 expression via transcriptional and post-transcriptional mechanisms. This possible TLR4-miR-155 positive feedback loop might result in the synergistic accelerating effect of TLR4 and miR-155 on CAC development.
\end{abstract}

Keywords: Toll like receptor 4, MicroRNA-155, Inflammatory bowel disease, Colitis-associated cancer, Positive feedback loop

\section{Background}

The vital roles of persistent infection and chronic inflammation in driving the initiation and progression of multiple malignancies, including cervical cancer, prostate cancer, liver cancer, gastrointestinal cancer, etc. have been acquired [1-6]. Persistent stimulation of epithelial cells and infiltration of immune cells caused by oncogenic pathogen infection and uncontrollable inflammation may

*Correspondence: wangjun@wust.edu.cn

${ }^{1}$ Hubei Province Key Laboratory of Occupational Hazard Identification and Control, Wuhan University of Science and Technology, Wuhan, China

Full list of author information is available at the end of the article create a tumor-favouring cellular microenvironment $[5$, 7]. Currently, colorectal cancer (CRC) is considered as the 3rd most common malignancy and the 4th leading cause of cancer-related deaths worldwide [8]. Despite that the exact etiology of CRC is still unknown, accumulative evidences have supported that patients with inflammatory bowel diseases (IBD), a group of chronic gut inflammatory disorders including ulcerative colitis (UC) and Crohn's disease (CD), are at a clearly increased risk for the CRC development [9-11]. IBD has been believed as an independent risk factor of CRC, the incidence of CRC in IBD patients has been reported to be up to $60 \%$ higher than that in the general population [12]. In particular, original author(s) and the source, provide a link to the Creative Commons licence, and indicate if changes were made. The images or other third party material in this article are included in the article's Creative Commons licence, unless indicated otherwise in a credit line to the material. If material is not included in the article's Creative Commons licence and your intended use is not permitted by statutory regulation or exceeds the permitted use, you will need to obtain permission directly from the copyright holder. To view a copy of this licence, visit http://creativecommons.org/licenses/by/4.0/. The Creative Commons Public Domain Dedication waiver (http://creativeco mmons.org/publicdomain/zero/1.0/) applies to the data made available in this article, unless otherwise stated in a credit line to the data. 
population-based evaluations suggested that the risk of CRC in patients with UC was between two- and threefold that of the general population [11]. Approximately $8 \%$ of UC patients developed CRC in 20 years and $18 \%$ in 30 years of disease [13]. Moreover, the local alteration of intestinal microbiota composition and metabolic activity has been linked to chronic inflammation in IBD and cancer development in colitis-associated cancer (CAC) [11]. It has been demonstrated that some specific species such as Fusobacterium nucleatum (a Gram-negative anaerobic bacterium) and Salmonella (a Gram-negative facultative anaerobic bacterium) might be the potential pathogens that play key roles in the progression of CAC $[4,11,14]$. Nevertheless, the molecular mechanisms of CAC development remain unclear.

As the most important pattern-recognition receptors (PPRs), Toll-like receptors (TLRs) could recognize the pathogen-associated molecular patterns (PAMPs) carried by diverse microorganisms and the danger-associated molecular patterns (DAMPs) derived from stressed or damaged cells, and are responsible for the activation and association of innate and adaptive immune responses [15, 16]. TLRs have been identified as main components of infection diseases, innate immunity, inflammatory conditions $[15,16]$, and importantly, inflammation-mediated tumorigenesis $[15,17,18]$. Up to date, different members of TLR family have been demonstrated to contribute to the involvement of inflammation in cancer progression [18-22]. For example, it has been reported that the expression of TLR2 gradually increased from normal mucosa, to Helicobacter pylori-gastritis, to metaplasia, to dysplasia [19]. Hong et al. [20] have demonstrated the role of TLR3/7-mediated signaling in the induction of CAC using a well-established murine model of azoxymethane (AOM)/dextran sulfate sodium (DSS) treatment. The role of TLR7 and TLR8 expression and signaling in chronic pancreatitis-linked pancreatic carcinogenesis has also been determined [21, 22].

In particular, more and more evidences $[7,23,24]$ have shown that the TLR4-mediated signaling might act as a pivotal pathogen-activated tumor signal pathway and an important carcinogenic mechanism involved in the development of CAC. As a key member of TLR family and a classic inflammatory mediator, TLR 4 acts as a bridge molecule between innate and adaptive immunity, as well as between infection and inflammation [25]. Especially in the gut, a high density of luminal microbes and the abundant PAMPs coexist with the intestinal mucosa [26]. TLR4 has been well-accepted as the main PRR as well as the canonical receptor for lipopolysaccharide (LPS) of Gram-negative bacteria, a group of predominant gut pathogens [27, 28]. Moreover, the intestinal invasion of CAC development-related pathogens such as $F$. nucleatum and Salmonella has been reported to target and activate TLR4 signaling [4, 11, 29]. As a type I transmembrane glycoprotein receptor containing 839 amino acids [30], TLR4 is widely expressed on various immune cells, epithelial/endothelial cells and tumor cells, etc. [31] Several auxiliary molecules including LPS binding protein (LBP), cluster of differentiation 14 (CD14), and myeloid differentiation factor 2 (MD-2) are required in the TLR4 receptor complex as co-receptors for TLR4 [31]. Once recognized, LPS can be transferred to cell surface CD14 by LBP, then bond with the TLR4/MD-2 receptor complex [31]. Subsequently, the LPS/MD-2/TLR4 complex recruits two distinct intracellular adaptor proteins including myeloid differentiation primary response gene 88 (MyD88)/MyD88 adaptor-like (Mal) and TIR-domaincontaining adapter-inducing interferon- $\beta$ (TRIF)/ TRIF-related adaptor molecule (TRAM), then triggers activation of two parallel signaling pathways, MyD88dependent pathway and MyD88-independent pathway, resulting in transcription of inflammatory cytokines, such as tumor necrosis factor- $\alpha$ (TNF- $\alpha$ ), interleukin- 6 (IL-6), IL-1, and secretion of type I interferons [32]. It has been reported that the TLR4/MD2 expression levels on intestinal epithelial cells are relatively low under normal conditions, but significantly upregulated during the development of IBD [33]. More importantly, disturbance of TLR4 pathway has been considered as one of the unique aspects of IBD-related colorectal tumorigenesis [34]. In this review, we summarized the current findings about the potential role of TLR4 during CAC progression, and its potential association with microRNA (miR)155, a CAC-related miRNA.

\section{Up-regulation of TLR4 in colitis and CAC}

In healthy adult mammals, TLR4 has been found to be lowly expressed in the intestinal epithelium, thereby limiting excessive inflammatory responses directing towards the numerous microbial pathogens in the enteric cavity $[33,35]$. However, the expression of TLR4 has been frequently reported to be markedly upregulated in the inflamed intestinal mucosa [36-39]. The significantly enhanced expression of TLR4 transcripts and cell surface protein was demonstrated in the crypt epithelial cells isolated from mucosal samples of UC patients when compared to normal controls [37]. Tan et al. [38] also reported that TLR4 was expressed on inflammatory cells in the intestinal lamina propria and submucosa of patients with UC at active phase, but not detected in healthy controls. Moreover, TLR4 expression levels were positively correlated with disease activity indices, endoscopy scores and histopathological scores [38]. In a study involving 41 patients with active or inactive IBD [39], TLR4 mRNA was shown to be significantly upregulated 
in biopsy tissues, specifically from patients with signs of active UC, the expression of which was approximately 13 times higher than healthy controls.

In addition, studies $[40,41]$ showed that the mRNA and protein of TLR4 were overexpressed in colonic mucosa of CRC patients compared with the controls. TLR4 expression in CRC was significantly correlated with tumor stage and cancer-related survival outcomes [42]. More importantly, Fukata et al. [23] have demonstrated that the epithelial TLR4 expression was gradually increased from the lesions of active UC to those of low-grade dysplasia, high-grade dysplasia and CAC in human samples, thus suggested a critical contribution of epithelial TLR4 in the induction of inflammation-induced intestinal tumorigenesis. This clinical finding has been supported by animal experimental data [43]. The gene expression of TLR4 was revealed to be increased in classic mouse models of acute and chronic colitis induced by DSS, and the highest level of TLR4 expression was seen in colonic tumors induced by AOM/DSS [43]. These results collectively showed that TLR4 might at least act as a biomarker for the progression of CAC.

\section{Role of TLR4 in CAC development and its possible mechanisms}

Further gain- or loss-of-function experiments [23, 43-45] demonstrated the gradually upregulated TLR4 during CAC development might not only act as a biomarker, but also play an important role in promoting colitis-associated tumorigenesis. Fukata et al. [23] found that, after administration of AOM/DSS, the number of colonic tumors in villin-TLR4 mice, a transgenic mouse model carrying a constitutively active TLR4 in the intestinal epithelium, was significantly higher than that in wild type (WT) mice. Using an antagonist TLR4 antibody, the study team [23] demonstrated that the inhibition of TLR4 markedly suppressed the development of colonic tumors in the WT mice. Whereas, in the TLR4 ${ }^{-1-}$ mice treated with AOM/DSS, the incidence of colorectal neoplasia as well as the size and severity of dysplasia were found to be significantly decreased compared to those in WT mice [43]. In addition, Makkar et al. [44] induced syngeneic tumor isografts by injection of mouse colon cancer CT26 cells into BALB/c mice, and found that TLR4 ${ }^{-1-}$ CT26 cell tumors grew more slowly than WT CT26 tumors. Shi et al. [45] reported that deficiency of TLR4 significantly reduced the number of intestinal tumors in $\mathrm{Apc}^{\mathrm{Min} /+}$ mice, a mouse model of spontaneous intestinal tumorigenesis.

The possible mechanisms underlying the potential carcinogenic role of TLR4 in CAC initiation and development might be as follow.

\section{Proliferation-promoting effect of TLR4}

In a DSS-induced acute experimental colitis model, TLR4 knockout mice were found to be deficient in the ability of epithelial repair in response to DSS-induced injury, suggesting that the proliferation-promoting effect of TLR4 signaling was required for basal resistance against DSS-induced acute intestinal injury [46]. However, based on this proliferation-promoting activity, it could be speculated that long-term and excessive upregulation of TLR4 signaling might lead to the initiation and development of CAC.

In villin-TLR4 mice, overexpression of TLR4 in intestinal epithelium has been demonstrated to result in the increased epithelial proliferation, the expansion of crypt epithelial cells and the development of spontaneous duodenal dysplasia [23]. Furthermore, treating villin-TLR4 mice with AOM led to robust colonic tumorigenesis, accompanied by the dramatic proliferation of cells in tumors and surrounding tissues [47]. In human colon cancer cell lines HT-29 and SW480, CCK8 assay showed that the cell proliferation was suppressed by the inhibition of TLR4 using TLR4 siRNA [48]. Similarly, Kuo et al. [49] challenged HT-29 cells with a nonapoptotic dose of LPS, and found that the increase of cell proportion in $\mathrm{S}$ and $\mathrm{G}_{2}-\mathrm{M}$ phases following LPS challenge was eliminated by gene silencing of TLR4. In Apc ${ }^{\mathrm{Min} /+}$ mice treated with F. nucleatum, the expression of cell cycle regulatory gene Cyclin D1 was found to be significantly decreased by inhibition of TLR4 using TAK-242 [50]. Makkar et al. [44] used BrdU as a proliferative marker, and showed that the proliferation in $\mathrm{TLR}^{-1-}$ CT26 cell tumor isografts was significantly impaired compared to that in CT26 WT tumor isografts. Another study [45] also found that the number of Ki67-positive proliferative cells was much higher in tissues from the $\mathrm{Apc}^{\mathrm{Min} /+} \mathrm{WT}$ mice than in tissues from the Apc $\mathrm{Ain} /+^{\mathrm{TLR}} 4^{-/-}$mice. Kuo et al. [49] reported that the tumor cell proliferation in AOM/DSS-induced CAC was significantly decreased by the administration of eritoran, a TLR4 inhibitor. Furthermore, the same study [49] explored the effect of TLR4 inhibition by eritoran or TLR4 siRNA in primary cultures of colonic tumor spheroids on tumor cell proliferation in vitro, and found that TLR4 inhibition suppressed the increase of spheroid growth and the acceleration of cell-cycle progression induced by LPS. These above findings suggested that TLR4 could promote the proliferation of intestinal epithelial cells and malignant cells, thus might act as a potent proliferative driver during the development of CAC. 


\section{Anti-apoptotic effect of TLR4}

Fukata et al. [51] have found that the TLR4 knockout mice showed enhanced intestinal epithelial cell apoptosis following DSS-induced acute colitis. This antiapoptotic effect of TLR4 has been considered to be beneficial in reducing acute intestinal injury and promoting mucosal repair [51, 52]. However, given its anti-apoptotic activity, overexpression of TLR4 during colonic inflammation could be speculated to protect malignant cells against apoptosis and further promote tumor cell growth.

In human colon cancer cell lines HT-29, SW480 and Lovo, flow cytometry analysis showed that a significantly high level of apoptosis induced by TNF-related apoptosis-inducing ligand (TRAIL) was attenuated by the typical TLR4 activator LPS [53]. Chung et al. [54] induced apoptosis of human colon cancer HCT-116, HT-29 and HCT-8 cells by oxaliplatin and 5-fluorouracil (5-FU). After treatment with oxaliplatin and 5-FU, cells were incubated with or without LPS. The results showed that the LPS treatment for $8 \mathrm{~h}$ significantly inhibited the apoptosis of drug-treated colon cancer cells, as evidenced by the increased expression of anti-apoptosis-related B-cell lymphoma 2(Bcl-2) family proteins and the decreased activity of pro-apoptosis caspase-3/7 [54]. In CT26 tumor isografts, the numbers of apoptotic cells and the activity of caspase-3, which were detected using TUNEL assay and immunofluorescence, respectively, were found significantly increased by TLR4 knockout [44]. In an invivo study conducted by Kuo et al. [55], TLR4-mut mice (TLR4-deficient mice harboring a point mutation in the TLR4 at Pro712) and their WT counterparts were used for AOM/DSS administration. Then the higher numbers of apoptotic cells per area of tumor were found in TLR4mut mice than in WT mice. This study [55] also explored the effect of TLR4 deficiency on cell apoptosis in colonic tissues by an ex-vivo experiment. The colonic tissues of TLR4-mut or WT mice were stimulated with LPS from the mucosal side. Enhanced epithelial apoptosis was found in colonic tissues of TLR4-mut, but not WT mice. These data confirmed that TLR4 could protect colonic cancer cells from cell apoptosis in vitro and in vivo.

However, a conflicting study conducted by $\mathrm{Li}$ et al. [56] showed that the constitutive activation of TLR4 in intestinal epithelium resulted in an elevation of intestinal tumor cell apoptosis levels and a reduction of intestinal tumor burden in the $\mathrm{Apc}^{\mathrm{Min} /+}$ mice, indicating that persistent epithelial activation of TLR4 might play a role in inhibiting intestine tumorigenesis by enhancing apoptotic signals. This finding appeared to be in contradiction with the study conducted by Kuo et al. [55] suggesting deficiency of TLR4 increased epithelial apoptosis in AOM/DSS mouse model. This contradiction might be due to the different animal models used in these studies. Li et al. [56] introduced the CD4-TLR4 transgene linked to an intestinal epithelial cell-specific promoter into $\mathrm{APC}^{\mathrm{Min} /+}$ mice. The authors attributed the pro-apoptotic effect of epithelial TLR4 activation on intestinal tumor cells to the downregulation of cyclooxygenase 2 (Cox-2), a major mediator of tumor survival and growth which can impart resistance to apoptosis, in CD4-TLR4expressing intestinal tumors [56]. However, Kuo et al. [55] observed the potential anti-apoptotic effect of TLR4 using TLR4-mutant mice harboring a spontaneous spontaneous point mutation of the TLR4 gene at Pro712 His (C.C3-Tlr4 $4^{L P S-d} / \mathrm{J}$ strain). The expression change of Cox-2 was not included in this study [55]. Nevertheless, Fukata et al. [51] reported that, using an AOM/ DSS-induced CAC mouse model, Cox-2 expression was significantly decreased in the mucosa of TLR4-deficient mice compared to that of WT mice. The enhanced Cox-2 levels were also observed in the villin-TLR4 transgenic mice generated using plasmids containing the mouse villin promoter (pBS-Villin) and the mCD4-hTLR4 fusion gene [23], in which CD4-TLR4 construct was expressed under a different epithelial promoter than the study conducted by Li et al. [56] Therefore, further researches on the regulatory mechanisms of TLR4 on Cox- 2 under different contexts (e.g. the presence or absence of inflammatory stimulation) or under different genetic backgrounds might be required to identify the role of TLR4 in regulating apoptosis of intestinal tumor cells.

\section{Role of TLR4 in invasion and metastasis}

High expression of TLR4-mediated signaling was found to be significantly associated with a high risk of liver metastasis and poor prognosis in CRC patients [57]. Ying et al. [58] explored the role of TLR4 signaling in the metastasis potential of mouse $\mathrm{C} 26$ and human colon cancer HCT-116 cells, and found that silencing of TLR4 expression significantly suppressed the LPS-induced migration and invasion of C26 and HCT116 cells, which were detected using wound healing assay and transwell assay, respectively. Subsequently, the study team [58] found that stimulation of TLR4 by LPS induced downregulation of epithelial marker E-cadherin and up-regulation of mesenchymal marker Vimentin, suggesting that activation of TLR4 signaling induced the epithelialmesenchymal transition (EMT) phenotype in colon cancer cells. EMT-like attributes have been well-accepted to greatly contribute to invasive phenotype and metastatic capacity of the migratory subpopulation in CRC [59]. In addition, Killeen et al. [60] showed that inhibition of TLR4 in human colon cancer SW480 and SW620 cells ameliorated tumor cell invasion and adhesion to the extracellular matrix, the latter of which has been 
considered as a key step in the process of tumor metastasis [61]. In an in-vivo study conducted by Hsu et al. [62], LPS-treated or untreated HT-29 cells were injected into athymic nude mice. After 5 weeks of incubation, the mice injected with LPS-treated HT29 cells were found to have a significantly higher number of liver surface metastatic nodules compared with those injected with untreated HT29 cells, and this effect exerted by LPS could be attenuated by TLR4 antagonist. Similarly, using a mouse model of colon cancer cell metastasis to lungs, another study [63] showed that MD2 blockage suppressed the metastatic capacity of colon cancer cells in vivo through inhibiting TLR4/MD2 signaling. These findings collectively suggested the potential role of TLR4 in enhancing the aggressiveness and metastatic ability of CRC cells.

\section{Involvement of TLR4 in tumor-favouring cellular microenvironment}

It has been well-accepted that the interaction between tumor cells and cells of the surrounding microenvironment could promote the progression of tumor [64]. TLR4 expression in the colonic tumor microenvironment has been found to be positively correlated with the disease progression of CRC [65]. During DSS-induced acute colitis, the production of chemokines, including $\mathrm{C}-\mathrm{C}$ motif chemokine ligand 2 (CCL2), CCL20 and Chemokine C-X3-C-Motif Ligand 1 (CX3CL1), as well as the infiltration of macrophages and dendritic cells (DCs) were found to be decreased in anti-TLR4 antibody-treated mice [66]. Using bone marrow (BM) chimeric mice to construct AOM/DSS-induced CAC model, Fukata et al. [24] reported that the infiltration of neutrophils and macrophages as well as the expression of chemokines CCL2 and keratinocyte-derived chemokine were higher in WT mice engrafted with TLR4 $4^{-1-} \mathrm{BM}$ than in $\mathrm{TLR} 4^{-1-}$ mice engrafted with WT BM, indicating that TLR4 signaling on colonic epithelial cells rather than the myeloid compartment could promote the recruitment of inflammatory cells in the tumor microenvironment of CAC. Furthermore, macrophages recruited in the tumor microenvironment could differentiate into tumor-promoting $M_{2}$-phenotype or tumor-suppressing $M_{1}$-phenotype [67]. Chen et al. [68] reported that inhibition of TLR4 by TAK242 significantly suppressed the in-vitro $\mathrm{M}_{2}$ polarization of macrophage Raw264.7 cells induced by F. nucleatum. The in-vivo study in F. nucleatum-treated $\mathrm{Apc}^{\mathrm{Min} /+}$ mice also showed that pre-treatment of TAK-242 significantly reduced the $\mathrm{M}_{2}$ polarization of macrophages within the tumor microenvironment [68]. These data indicated that TLR4 signaling upregulated in colitis might contribute to the creation of tumour-favouring microenvironment during the development of CAC.

\section{Potential role of miR-155, a CAC-related miRNA, in regulating TLR4 signaling}

In recent years, based on the above potential roles of TLR4 in CAC development and progression, much attention has been focused on the regulation of TLR4 signaling in the context of colitis-associated tumorigenesis. Many TLR4-related signaling molecules, such as NF- $\mathrm{kB}$, PI3K/Akt, Wnt/ $\beta$-catenin, EGFR, GSK3 $\beta$, Erk1/2, JNK and Nox1 [30, 38, 49, 68, 69], have been reported to be implicated in the mechanisms underlying the role of TLR4 in CAC.

In particular, as a high-profile mechanism to silence gene expression, miRNA-mediated post-transcriptional regulation has been found to contribute to the control of TLR4 signaling pathway [70,71]. miRNAs are a group of small endogenous non-coding RNAs of $\sim 22$ nucleotides that regulate gene expression by binding to the 3'-untranslated regions (UTRs) of target mRNAs, leading to mRNA degradation or translation breakdown [72, 73]. Among the multiple miRNA molecules regulating TLR4 pathway, miR-155 captures our attention because of its highly similar role to TLR4 in the pathogenesis of CAC.

It has been frequently demonstrated that the miR-155 expression is markedly increased in inflamed colonic mucosa of UC patients [74-77]. The fold changes of miR-155 expression levels in inflamed human UC samples compared to the controls were reported to range from 1.22 to 2.33 [75, 76]. In DSS-induced acute colitis animal model, miR-155 antagomir dramatically distributed in colon epithelial and submucosal cells was significantly upregulated by DSS challenge, with fold change of 4.74 compared to the normal controls [78]. Importantly, El-Daly et al. [79] had applied the stepwise CAC model induced by AOM/DSS to detect the aberrant expression of miR-155 during the different stages of CAC development. The results showed that the expression of miR155 was gradually increased as the mouse colonic tissue transformed from normal to actively inflamed to malignant state, suggesting that miR-155 might play a role in the progression of CAC. Coincidently, this dynamic change of miR-155 expression in a stepwise pattern was consistent with that of TLR4 during stages of CAC development observed by Fukata et al. [43]

As a multi-functional microRNA, miR-155 has been found to markedly promote cell proliferation and proinflammatory secretions, regulate the immune balance in colonic mucosa of IBD, thus contribute to the pathogenesis of experimental colitis $[80,81]$. Importantly, the function of miR-155 in CAC promotion has been demonstrated in miR-155 deficient mice exposed to AOM/DSS challenge [82]. Compared to syngeneic WT mice, host miR-155 deficiency significantly decreased the tumor incidence and the multiplicity of colonic neoplasms. This 
study [82] also showed a similar inhibitory effect posed by miR-155 deficiency on the in-vivo growth of transplantable mouse colon cancer MC38 tumors in mice. In human colon cancer cell lines SW480 and HCT116, hypoxanthine phosphoribosyltransferase assay showed that the mutation rate was increased along with the upregulation of miR-155 expression levels during doxycycline treatment [83]. This finding established a direct link between the mutation rate and the miR-155 expression level in colon cancer cells, suggesting that miR-155 might promote colonic tumorigenesis based on its mutant phenotypes. Transfection of HCT-116 cells with miR-155 mimics significantly inhibited the cell apoptosis, and promoted the proliferation, cell cycle progression and invasive abilities [84]. Whereas, the cell growth, motility and invasion of human colon cancer cell lines SW480, DLD-1, LS174T have been found to be inhibited by knockdown of miR-155 [85]. These findings collectively suggest that miR-155 might act as an oncogenic miRNA during the development of CAC, which is also similar to the abovementioned CAC-promoting effect of TLR4.

However, Velázquez et al. [86] presented a contrary evidence, and showed that administration of AOM/ DSS to miR-155 $5^{-1-}$ mice caused an increased number of polyp/adenoma and a higher grade of epithelial dysplasia than the administration to WT controls, indicating that miR-155 might protect against the development of CAC. This finding was in contradiction with the report of Chen et al. [82]. As both studies used a similar AOMDSS administration protocol, this contradiction might be due to the difference in the experimental environment or the genetic background of experimental mice. Therefore, further research and replication should be conducted to verify the oncogenic property of miR-155 in CAC.

Of note is the potential regulatory activity of miR155 for TLR4 signaling (Table 1). Currently, miR-155 has been considered as a critical regulator of innate/ adaptive immune response and TLRs signaling [87, 88]. Marques-Rocha et al. [89] found an evidence showing that miR-155 might exert a direct inhibitory control over TLR4 expression. In this study, overexpression of miR155 by transfection of miR-155-3p mimic significantly downregulated the expression of TLR4 in human acute monocytic leukemia THP-1 cells and THP-1-derived macrophages [89]. However, another study [90] showed that transfection with miR-155 mimic resulted in the significantly increased expression of TLR4 in human $\mathrm{HaCaT}$ keratinocytes. In an experimental autoimmune prostatitis model, Fu et al. [91] found that the expression of TLR4

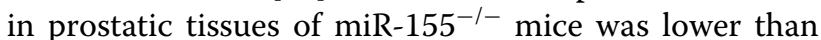

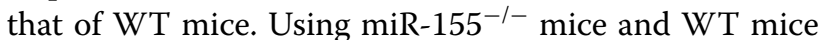
to establish permanent middle cerebral artery occlusion model, Wen et al. [92] showed that TLR4 expression was significantly decreased in the ischemic cerebral tissues of miR-155 $5^{-1-}$ mice compared with that in WT mice, whereas overexpression of miR-155 induced by pAd-miR-155 transfection markedly increased the TLR4 expression in ischemic cerebral tissues. Therefore, further studies in more cell lines and more animal models should be conducted to verify the exact regulatory role of miR-155 for TLR4 signaling.

As for the possible regulatory mechanisms, several studies [70, 92-94] have demonstrated that miR-155 could augment TLR4 signaling through targeting suppressor of cytokine signaling 1 (SOCS1), a key negative regulator of TLR4 signaling [93]. Wang et al. [94] revealed that transfection of mouse primary macrophages with miR-155 mimics enhanced TLR4 responsiveness, which was manifested as enhanced production of LPS-induced TNF- $\alpha$ and nitric oxide (NO); importantly, luciferase assay showed that miR-155 directly targeted 3' UTR of SOCS1. Similarly, Chen et al. [93] showed that overexpression of miR-155 in $\mathrm{VDR}^{-1-}$ bone marrow derived macrophages (BMDMs) treated with LPS resulted in the markedly reduced expression of SOCS1, as well as a much more robust and prolonged production of proinflammatory cytokines TNF- $\alpha$, IL- 6 and IL- $1 \beta$, suggesting miR-155 could enhance and prolong TLR4-mediated inflammatory responses through excessive inhibition of SOCS1. In oxygen-glucose deprivation-treated microglia BV2 cells, overexpression or knockdown of miR-155 could respectively promote or inhibit TLR4 expression, which was also accompanied by the reduced or increased expression of SOCS1, respectively [92]. These data highly suggested that miR-155 might act as a direct inhibitor of SOCS1, thus play an indirect upregluatory role for TLR4 signaling.

Interestingly, it has been reported that the expression of SOCS1 protein was significantly suppressed in peripheral blood mononuclear cells (PBMCs) of primary sclerosing cholangitis (PSC) patients compared with controls, importantly, which was accompanied by a significant enhancement of miR-155 expression indicating miRNA155-modulated SOCS1 expression [95]. In fact, PSC frequently co-occurs in patient with IBD, the presence of concomitant PSC with IBD represents a distinct disease phenotype that carries a higher risk of CRC [96, 97]. UC patients with concomitant PSC has been reported to bear a tenfold increased risk of CRC, compared to patients with UC alone [97]. Moreover, upregulation of TLR4 signal has also been found in PSC patients $[98,99]$. Therefore, it is necessary to further explore the relationships among miR-155, SOCS1 and TLR4, especially in UC patients with concomitant PSC.

In addition, miR-155 has been reported to enhance TLR4 signaling by inhibiting Src homology 2 


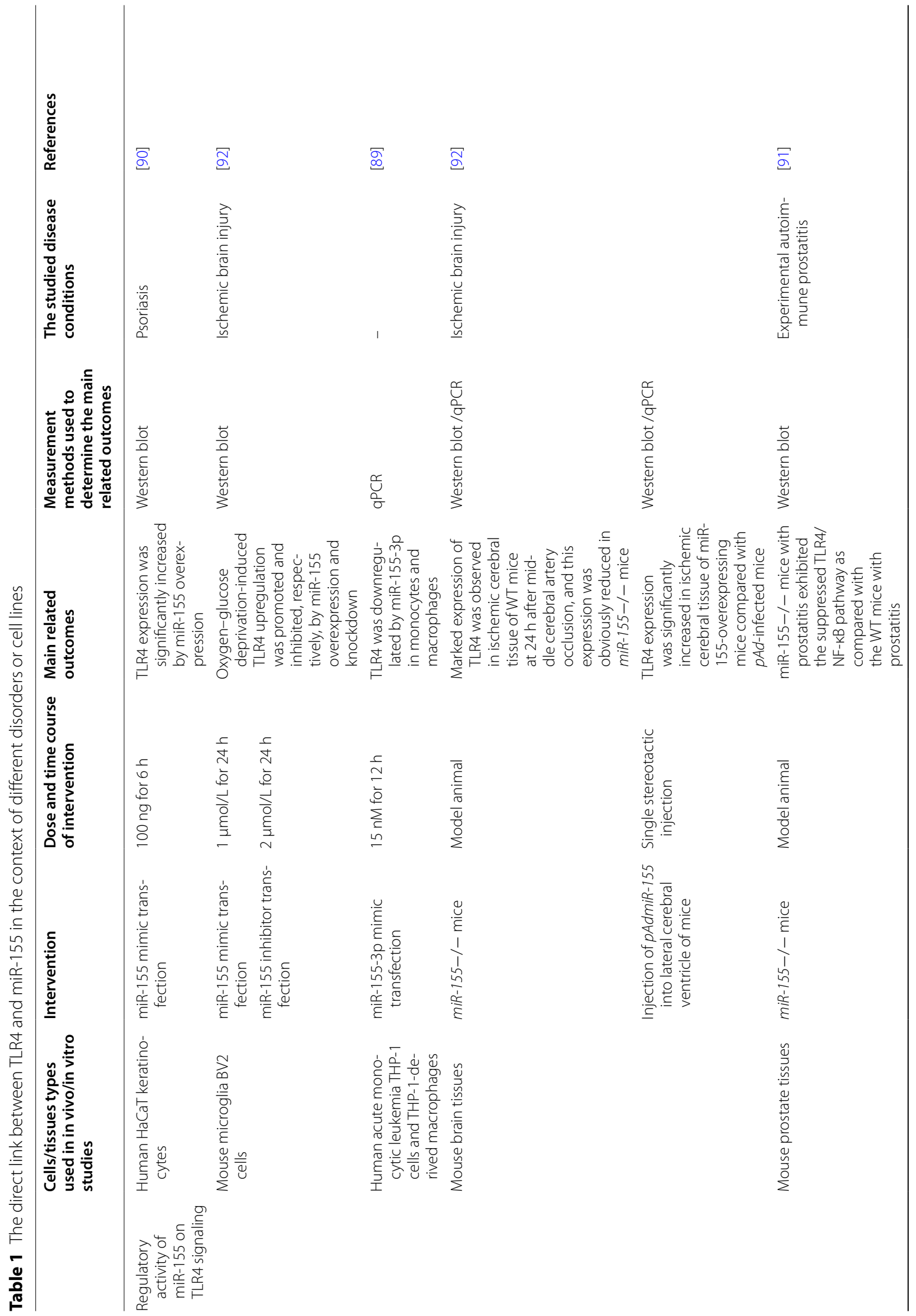




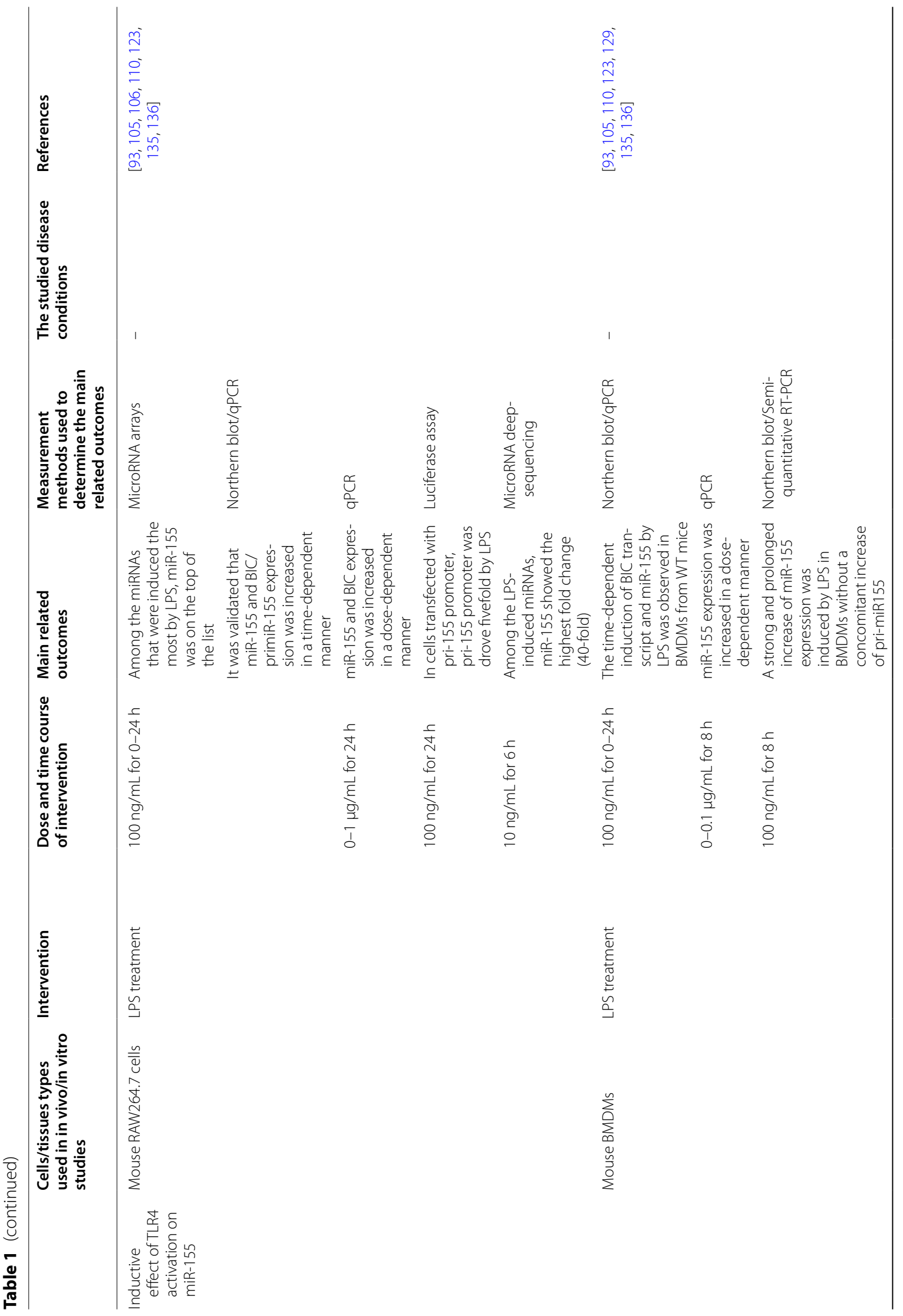




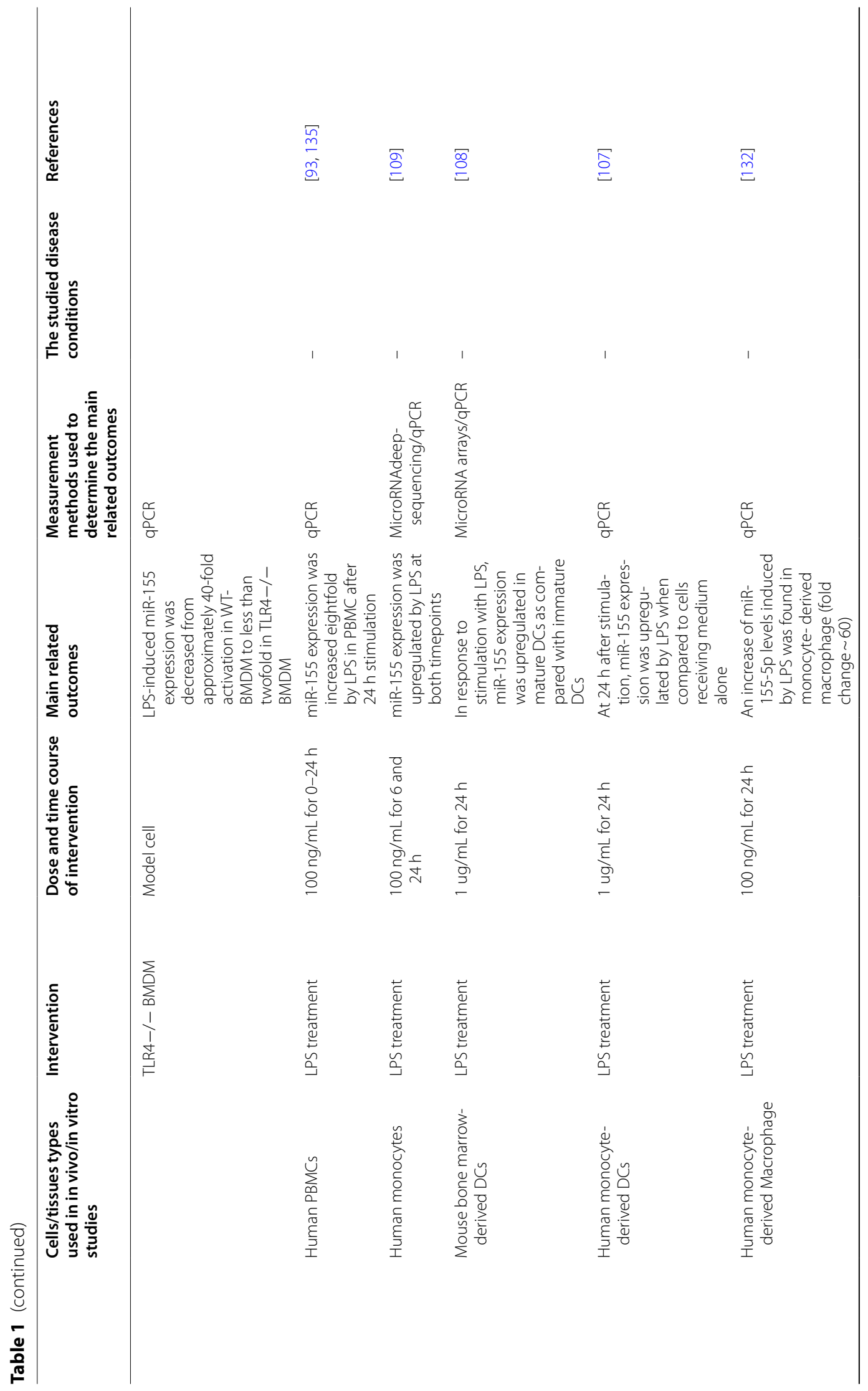




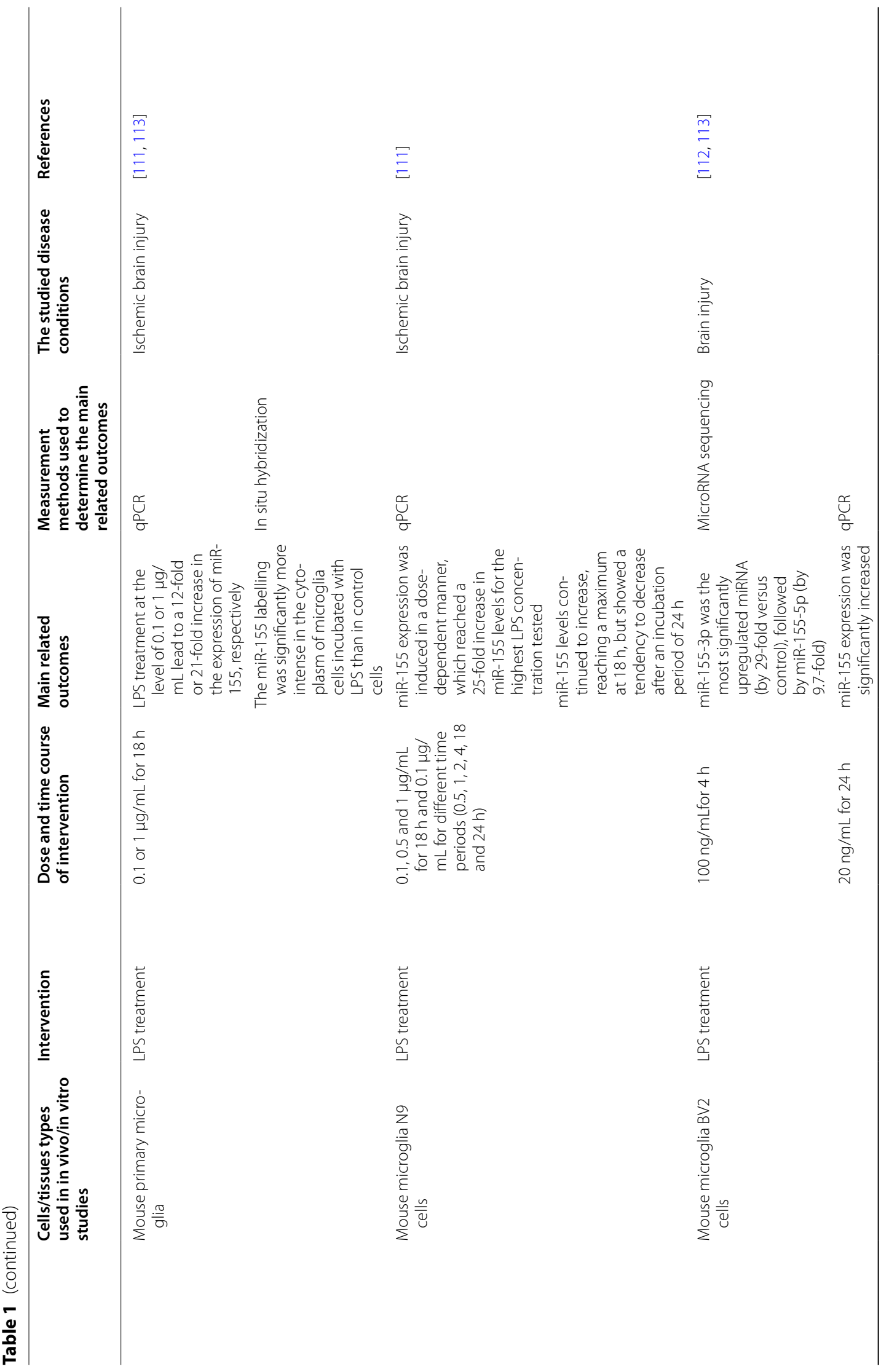




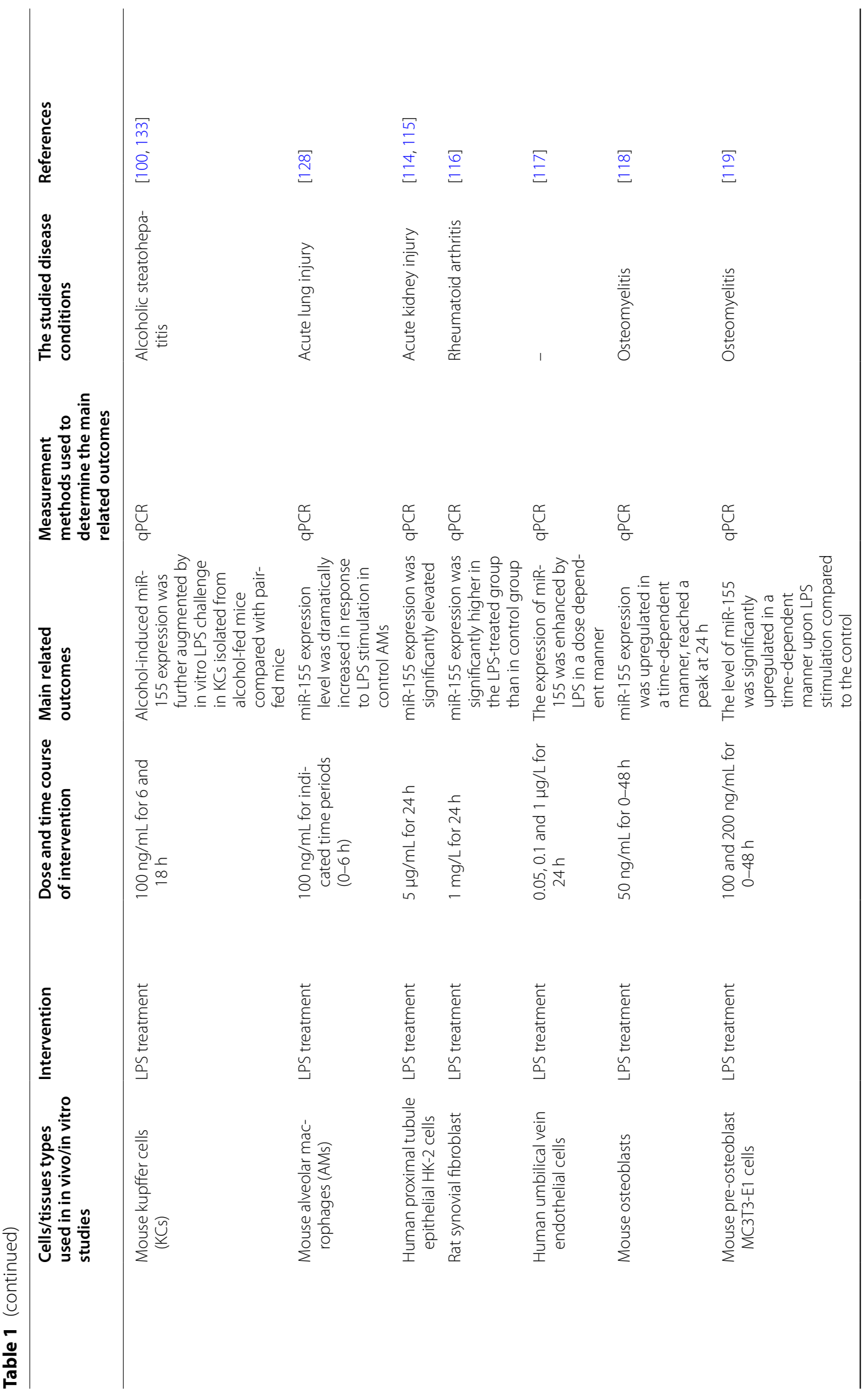




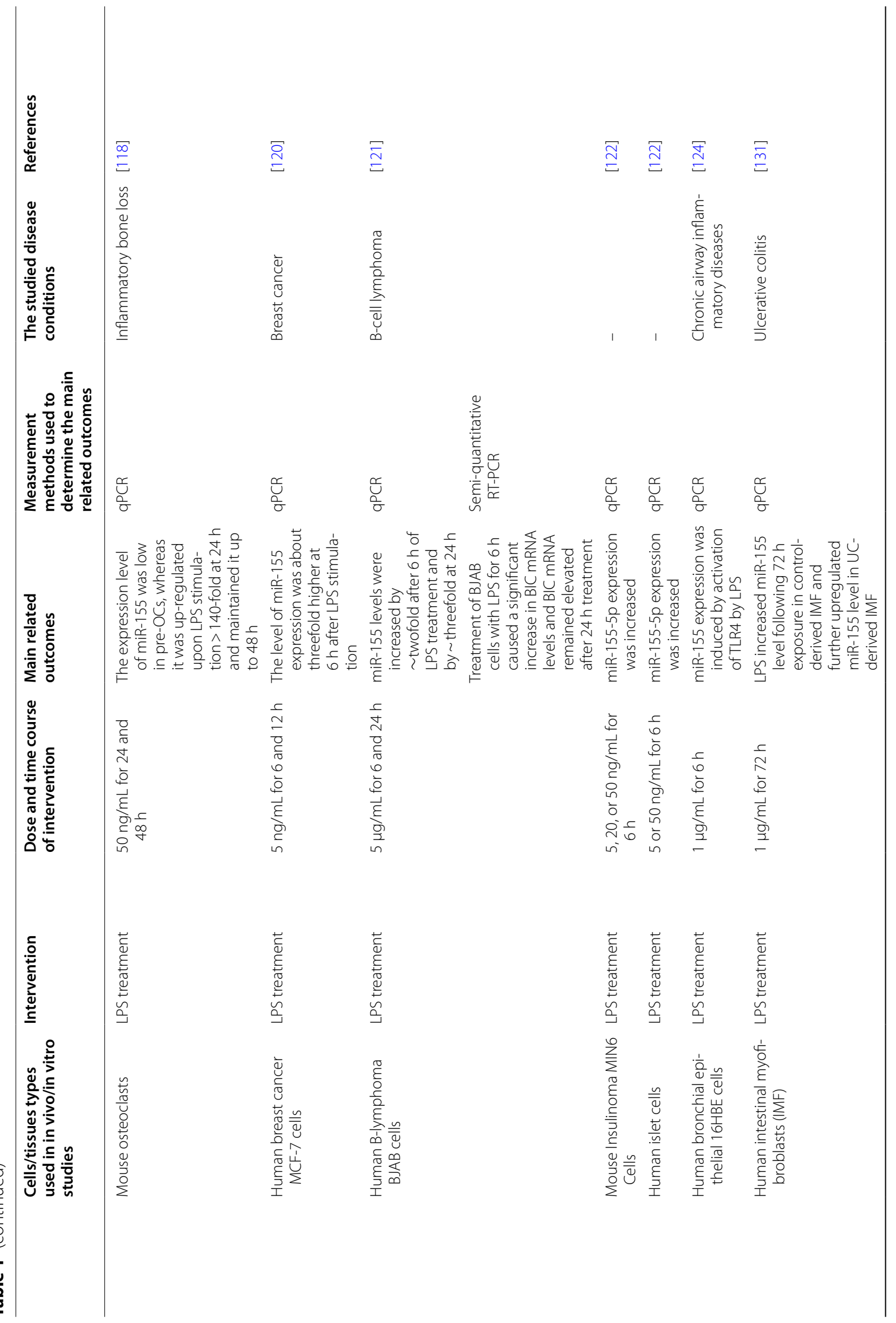




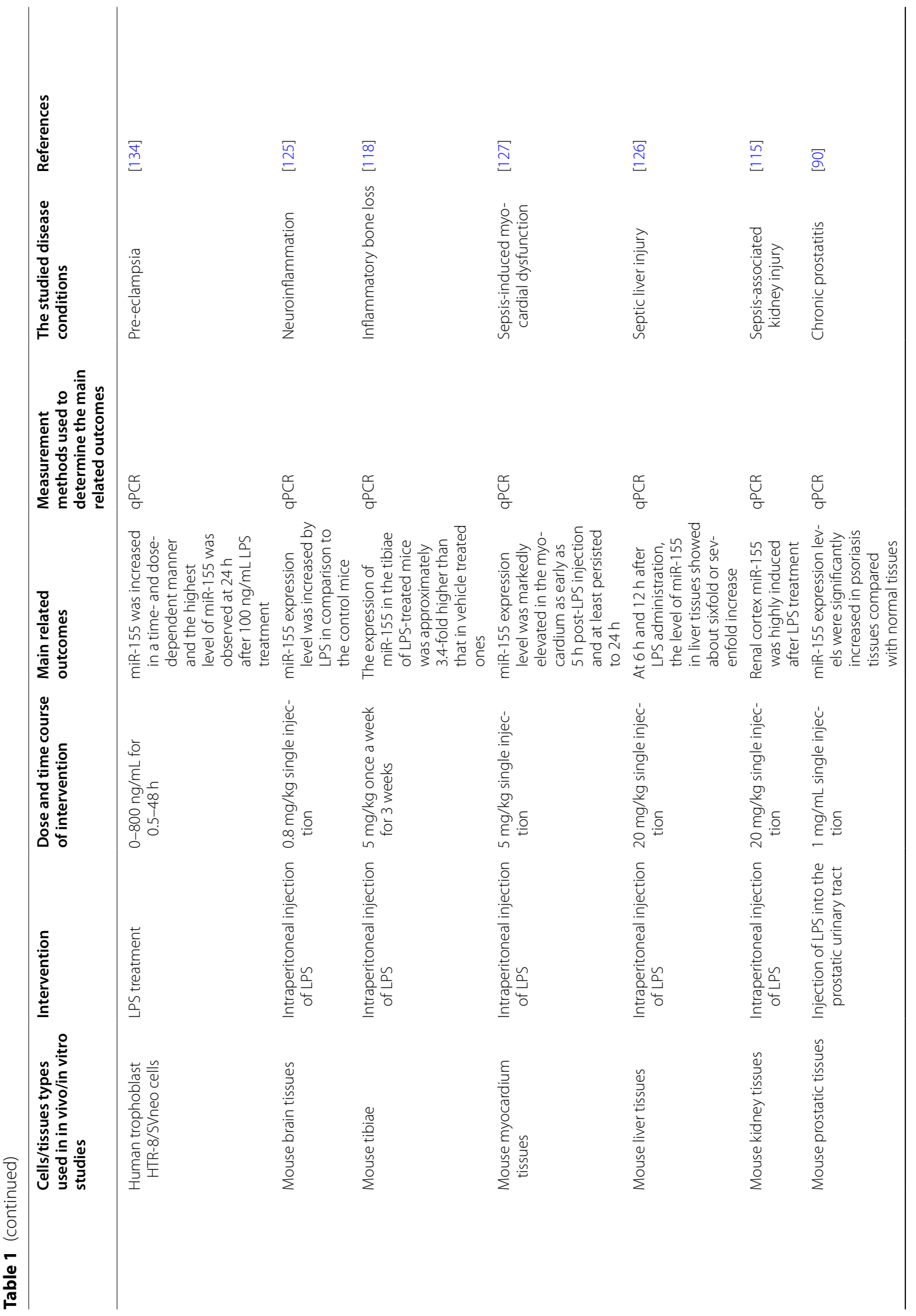




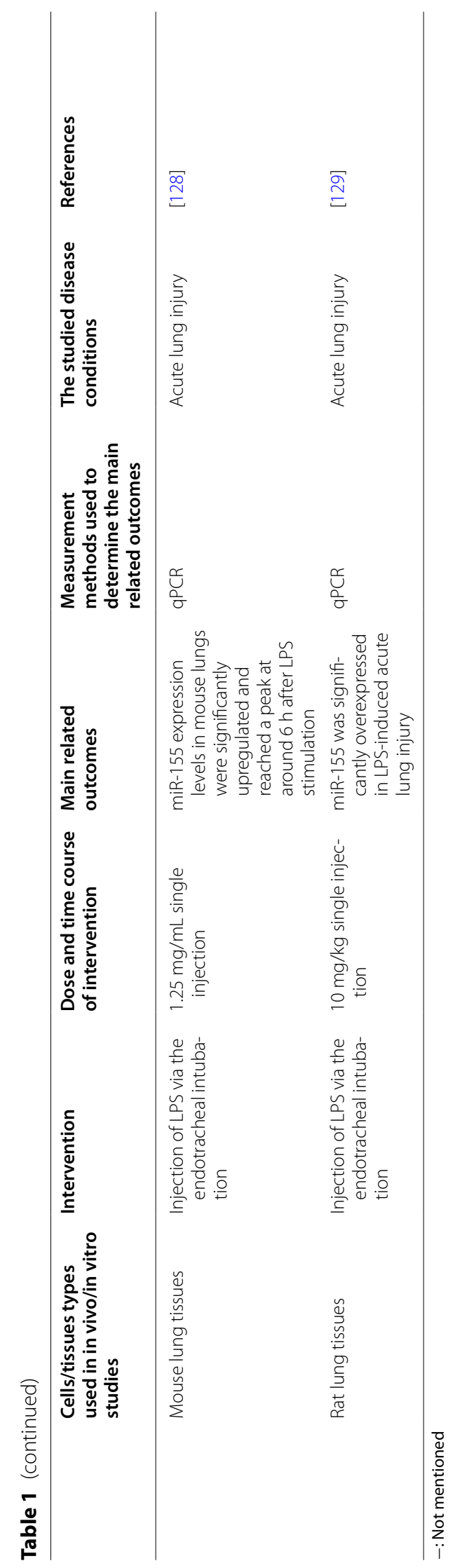


domain-containing inositol-5'-phosphatase 1 (SHIP1) $[100,101]$, the latter of which has been demonstrated to negatively regulate LPS/TLR4-mediated inflammatory response via suppression of LPS-induced combination between TLR4 and MyD88 [102]. MiR-155 has been demonstrated to directly bind to the $3^{\prime}$-UTR of SHIP1 mRNA, and induce a significant reduction in SHIP1 expression in primary BMDMs and Raw264.7 cells [80]. Accordingly, the in-vivo study showed a significantly increased SHIP1 expression, along with decreased inflammatory responses, in the antagomiR-155-treated mice [80]. In LPS or alcohol-pretreated liver kupffer cells (KCs), Bala et al. [100] reported that overexpression and inhibition of miR-155 could increase and decrease the SHIP1 expression, respectively. Another study [101] showed that transfection of primary microglia with miR155-5p mimics significantly repressed the luciferase activity in SHIP1 $3^{\prime}$ UTR, and downregulation of miR155-5p significantly attenuated TLR4-mediated activation of NF- $\mathrm{KB}$ and release of TNF- $\alpha$ and IL-1 $\beta$.

\section{Inductive effect of TLR4 activation on miR-155}

On the other hand, miRNAs are also modifiable molecular targets. Accumulative evidences [91, 93, 100, 103-131] have indicated the role of miR-155 as one of TLR4-responsive miRNAs. It has long been recognized that miR-155 was processed from B-cell integration cluster (BIC) transcripts (or pri-155) and was highly induced in immune cells in response to various TLR ligands [103, 104]. In particular, the inductive effect of specific TLR4 ligand LPS on miR-155 has been verified in various invitro experiments using primary cells and immortalized cell lines (Table 1). In mouse Raw264.7 macrophages, BMDMs and human PBMCs, the in-vitro stimulation with LPS caused significant increases in the transcript expression levels of miR-155, which was on the top of the list of LPS-induced microRNAs identified by miRNA microarrays [93]. These increases were further validated by Northern blot and qPCR analyses [93, 105, 106]. In addition, utilizing the same analysis methods, the increased expression of miR-155 was also observed in human/murine primary DCs activated with LPS [107, 108]. Using a semi-quantitative RT-PCR method, Lu et al. [109] showed that the expression levels of both mature and precursor forms of miR-155 were robustly induced in LPS-treated primary human monocytes. In Raw264.7 cells, luciferase assay showed that LPS could drive the induction of pri-155 promoter in a dose-dependent manner, indicating that miR-155 might be regulated by LPS at the transcriptional level [110]. Treatment of mouse microglia N9 cells with increasing concentrations of LPS resulted in a significant and dose-dependent increase of miR-155 expression, which reached a 25-fold increase at the highest LPS concentration tested [111]. Similarly, a significant increase of miR-155 expression was also found in LPS-stimulated mouse primary microglia or immortalized BV2 cells $[112,113]$. In the $\mathrm{KCs}$ isolated from alcohol-fed and pair-fed mice, Bala et al. [100] found that the alcohol-induced expression of miR-155 was significantly amplified by in-vitro LPS stimulation when compared with pair-fed mice. Besides, LPS-induced upregulation of miR-155 has also been demonstrated in non-immune cells. Treatment of human proximal tubule epithelial HK-2 cells with LPS for $24 \mathrm{~h}$ resulted in a significantly elevated expression of miR$155[114,115]$. LPS increased expression levels of miR155 in rat primary synovial fibroblasts, an in-vitro model for rheumatoid arthritis [116]. Treating human primary umbilical vein endothelial cells with LPS $(0.05-1 \mu \mathrm{g} / \mathrm{L})$ for $24 \mathrm{~h}$ enhanced the expression of miR-155 in a dosedependent manner [117]. In mouse primary osteoblasts and osteoclasts, miR-155 expression was found to be upregulated in a time-dependent manner upon LPS stimulation $[118,119]$. The similar upregulation of miR-155 upon LPS stimulation was also found in several tumor cell lines, including human breast cancer MCF-7 cells, B-lymphoma BJAB cells and mouse insulinoma MIN6 cells [120-122]. In order to clarify whether LPS-induced miR-155 expression is TLR4-dependent, De Santis et al. [123] treated BMDMs derived from WT-and TLR4 ${ }^{-/-}$ mice with LPS for $2 \mathrm{~h}$, and showed that the expression of miR-155 was upregulated in WT-BMDMs by 40 -fold, but was decreased to less than twofold in TLR4 ${ }^{-1-}$-BMDMs. Liu et al. [124] treated human bronchial epithelial 16HBE cells with TLR4 inhibitor prior to exposure to LPS, and found that LPS-induced upregulation of miR-155 was significantly attenuated by TLR4 inhibition.

In addition, the inductive effect of LPS on miR-155 has also been frequently verified in vivo (Table 1). Using the LPS-induced sepsis model, several studies [113, 125127] have observed the significant increases of miR- 155 expression in the brain, myocardium, liver and kidney tissues of mice challenged with LPS. Fu et al. [91] reported that LPS further enhanced the upregulation of miR-155 in the prostatic tissues of mice with experimental autoimmune prostatitis. In a LPS-induced acute lung injury animal model, miR-155 expression was found to be significantly upregulated in the lungs of mice and rats, and reached a peak at $6 \mathrm{~h}$ of LPS stimulation $[128,129]$. Bala et al. [130] also observed an increase of miR-155 levels in the livers of WT mice following LPS or alcohol treatment, which was significantly eliminated by knockout of TLR4.

Despite the fact that there are lack of experiments on the human intestinal cells, e.g. Caco-2, which is originally derived from a colon carcinoma, the above 
evidences on the link between miR-155 and TLR4 from studies on human epithelial cell lines, including human proximal tubule epithelial HK-2 cells [114, 115], human breast cancer MCF-7 cells [120] and human bronchial epithelial 16HBE cells [124], laid the foundation for the possible existence of this interaction in the intestinal mucosa. Notably, Pathak et al. [131] reported that LPS increased miR-155 levels in intestinal fibroblasts and myofibroblasts isolated from health colonic mucosa, and this increase was further enhanced in those from UC patients, which suggested that the above link between miR-155 and TLR4 existed in the context of colitis and might play a role in colitis development.

Based on the above findings on the inductive effect of TLR4 activation on miR-155 expression, several studies [132-136] have been conducted to explore the possible underlying molecular mechanisms. Nuclear factor- $\mathrm{k} B$ (NF-kB) and activator protein 1 (AP-1) have been identified as important transcription factors downstream of TLR4 [32]. Arboleda et al. [132] showed that inhibition of NF- $\mathrm{KB}$ by SC-514, an inhibitor of IKK- $\beta$ (a subunit of the NF-kB activation complex), diminished LPS-induced increase of miR-155-5p levels in human monocyte-derived macrophages. Using different NF- $\mathrm{kB}$ inhibitors, this finding was validated in LPS-treated Raw264.7 cells and mouse KCs $[133,134]$. Dai et al. [134] demonstrated that NF-kB p65 and AP-1 family members JunB, FosB directly bound to the BIC/ miR-155 promoter and promoted the transcription of miR-155, which were detected using DNA precipitation assay and luciferase assay, respectively, in human trophoblast cell HTR-8/SVneo after LPS treatment. In Raw264.7 cells, McCoy et al. [135] found that the transcription factor AP-1 might be required for BIC gene induction in response to LPS stimulation, thus play a role in the LPS induction of miR-155. In addition, Quinn et al. [110] reported that miR-155 promoter was controlled by Ets family of transcription factors, in which Ets2 was strongly induced by LPS. This study team also found that LPS-induced pri-miR-155 expression was significantly reduced in macrophages isolated from the Ets $2^{-1-}$ mice, verifying the importance of Ets2 in LPS-mediated induction of miR-155. Moreover, knockdown of $\mathrm{KH}$-type splicing regulatory protein (KSRP, a single-strand RNA-binding protein that bound to the terminal loop of miRNA precursors and promoted their maturation) could cause a decrease of mature miR-155 expression in LPS-treated BMDMs and Raw264.7 macrophages, whereas the expression of pri-miR-155 was not affected, suggesting that posttranscriptional mechanisms might also be involved in LPS-induced miR-155 expression [136].

\section{A possible TLR4-miR-155 feedback loop in CAC}

Collectively, in the context of different disorders or cell lines, miR-155 has been extensively found to act as a potential TLR4 signaling upregulation mechanism. While TLR4 activation would instead enhance the miR155 expression to constitute a TLR4-miR-155 positive feedback loop (Fig. 1). Once this feedback loop could be verified in the context of CAC, based on the similar dynamic expression changes of miR-155 and TLR4 during CAC development, as well as their similar functions in CAC promotion, it could be speculated that this TLR4miR-155 positive feedback loop would lead to the maintenance and amplification of oncogenic effects of TLR4 signaling, ultimately resulting in the synergistic accelerating effect of TLR4 and miR-155 on CAC development.

\section{Limitations and further directions}

About 20 miRNAs have identified to be involved in the regulation of TLR signaling pathways [137]. Among them, miR-155, miR-21 and miR-146a are the three miRNAs that received extensive attention due to their sensitive expression changes following TLRs activation and their regulatory roles in TLRs signaling [88]. Especially, miR-155 and miR-21 are also considered as the most prominent miRNAs playing central roles in molecular dysfunctions linking inflammation with cancer [138]. Based on the more abundant evidences on potential link between TLR4 and miR-155, as well as their similar dynamic expression changes during CAC development and their similar CAC-promoting effects, this review focused only on miR-155, in an attempt to present a reasonable hypothesis for the potential association between TLR4 and miR-155 in the context of CAC. Nevertheless, other TLR4-related miRNAs and their potential roles in CAC should be further summarized. For example, the negative regulation of TLR4 via targeting of the proinflammatory tumor suppressor PDCD4 by the miR-21 in CRC has been reported [138]. However, other studies $[139,140]$ reported that miR-21 acted as one of the positive factors that trigger the inflammatory feedback loop, thus induced and maintained the transformed state. Accordingly, miR-21 has been believed to be involved in both positive and negative feedback loops that control inflammation and CRC [138].

\section{Conclusions}

In summary, both clinical and experimental evidences showed a gradual increase of TLR4 expression during different stages of CAC development. As a classic PRR, TLR4 might act as a key bridge molecule between the infection of oncogenic pathogens (such as F. nucleatum and Salmonella) and the colonic inflammatory process. 


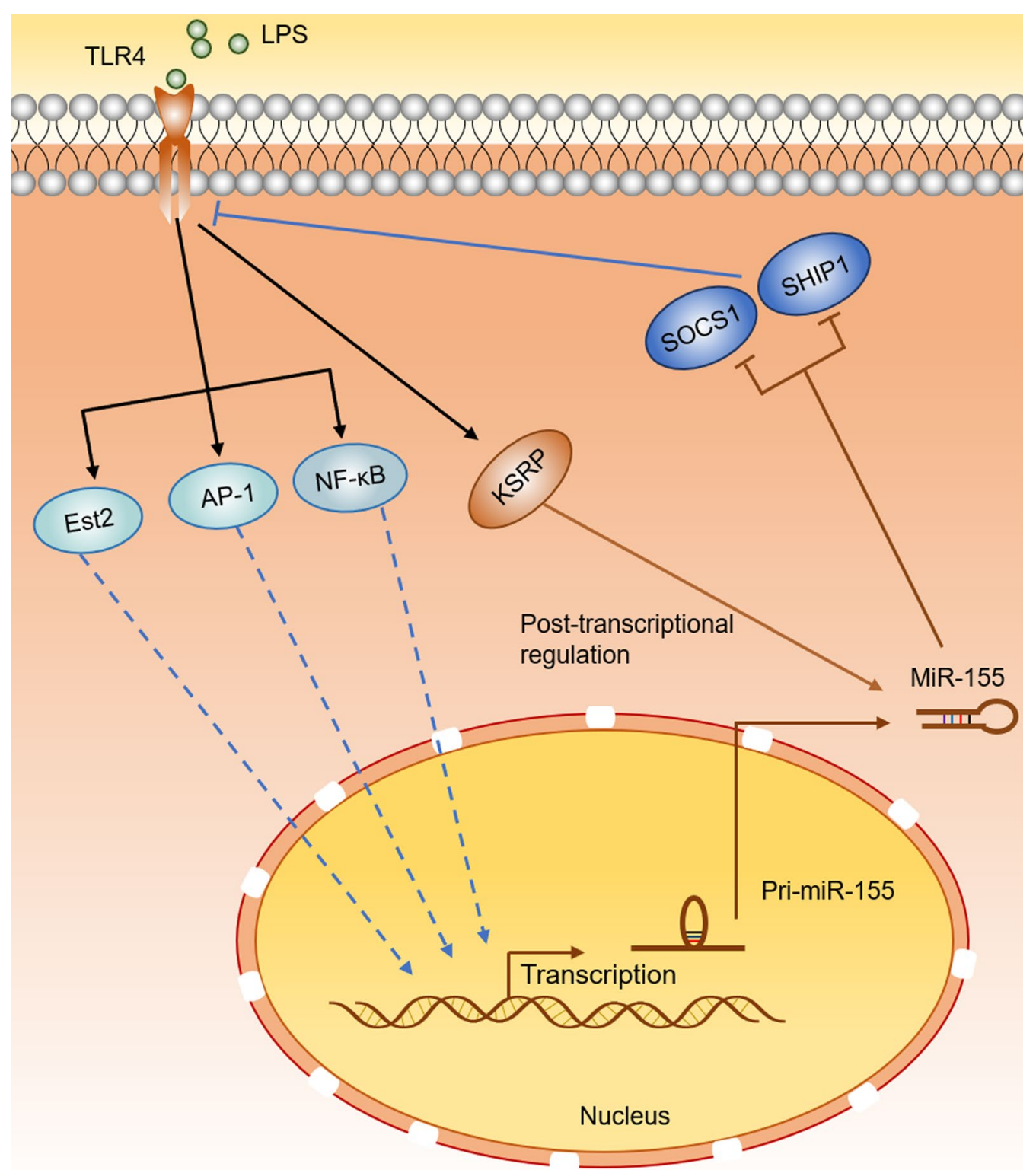

Fig. 1 Model of possible TLR4-miR-155 positive feedback loop. LPS-activated TLR4 signaling might promote the transcription of pri-miR-155 by triggering transcription factors such as NF-kB, AP-1, Ets2, and might enhance the maturation of miR-155 through a post-transcriptional mechanism depending on the induction of KSRP. These events might result in the overexpression of miR-155. The high level of expressed miR-155 might target SOCS1 and SHIP1, two key negative regulators of TLR4 signaling, thereby promoting the expression of TLR4, and ultimately constituted a TLR4-miR-155 positive feedback loop

More importantly, the upregulated TLR4 in colitis could play an important role on inflammation-induced intestinal tumorigenesis by promoting cell proliferation, protecting malignant cells against apoptosis, facilitating invasion and metastasis, as well as contributing to the creation of tumor-favouring cellular microenvironment. In particular, this review highlights the interplay between TLR4 and miR-155, a CAC-related
miRNA. These two molecules shared highly similar dynamic changes during stages of CAC development as well as highly similar CAC-promoting effects. In the context of different disorders or cell lines, miR-155 has been found to augment TLR4 signaling through targeting negative regulators SOCS1 and SHIP1; and TLR4 activation could induce miR-155 expression via transcriptional and post-transcriptional mechanisms, 
which might constitute a TLR4-miR-155 positive feedback loop. The further studies on this TLR4/miR-155 interplay in the context of CAC would facilitate the development of novel strategies for CAC prevention and control [67].

\begin{abstract}
Abbreviations
AOM: Azoxymethane; AP-1: Activator protein 1; BCl-2: B-cell lymphoma 2; BIC B-cell integration cluster; BM: Bone marrow; BMDMs: Bone marrow derived macrophages; CAC: Colitis-associated cancer; CCL: C-C motif chemokine ligand; CD: Crohn's disease; CD14: Cluster of differentiation 14; Cox-2: Cyclooxygenase 2; CRC: Colorectal cancer; CX3CL1: Chemokine C-X3-C-Motif Ligand 1; DCs: Dendritic cells; DSS: Dextran sulfate sodium; EMT: Epithelialmesenchymal transition; FU: Fluorouracil; IBD: Inflammatory bowel diseases; IL: Interleukin; KCs: Kupffer cells; KSRP: KH-type splicing regulatory protein; LBP: LPS binding protein; IMF: Intestinal myofibroblasts; LPS: Lipopolysaccharide; MD-2: Myeloid differentiation factor 2; miR-155: MicroRNA-155; MyD88: Myeloid differentiation primary response gene 88; NF-kB: Nuclear factor-kB; NO: Nitric oxide; OGD: Oxygen-glucose deprivation; PAMPs: Pathogenassociated molecular patterns; PPRs: Pattern-recognition receptors; PSC: Primary sclerosing cholangitis; SHIP1: Src homology 2 domain-containing inositol-5'-phosphatase 1; SOCS1: Suppressor of cytokine signaling 1; STAT : Signal transducer and activator of transcription; TLR4: Toll like receptor 4; TNF-a: Tumor necrosis factor-a; TRAIL: TNF-related apoptosis-inducing ligand; TRAM: TRIF-related adaptor molecule; TRIF: TIR-domain-containing adapterinducing interferon- $\beta$; UC: Ulcerative colitis; UTRs: 3'-Untranslated regions; WT: Wild type.
\end{abstract}

\section{Supplementary Information}

The online version contains supplementary material available at https://doi. org/10.1186/s12964-021-00771-6.

\section{Acknowledgements}

None

\section{Authors' contributions}

JG and ML drew the figure; JG and JW made a substantial contribution to the writing. All authors have read and approved the final manuscript.

\section{Funding}

This study was supported by funds provided by the National Natural Science Funding of China (Grant No.:71974153, 81602108).

\section{Availability of data and material}

This article reviews literature and therefore does not contain any associated data and materials.

\section{Declarations}

\section{Ethics approval and consent to participate}

Not applicable.

\section{Consent for publication}

Not applicable.

\section{Competing interests}

The authors declare that there is no competing interests.

\section{Author details}

${ }^{1}$ Hubei Province Key Laboratory of Occupational Hazard Identification and Control, Wuhan University of Science and Technology, Wuhan, China. ${ }^{2}$ New Medicine Innovation and Development Institute, Department of Pharmacy, College of Medicine, Wuhan University of Science and Technology, Wuhan, China.
Received: 16 April 2021 Accepted: 29 July 2021

Published online: 03 September 2021

\section{References}

1. Yang Y, Feng R, Wang YZ, Sun HW, Zou QM, Li HB. Toll-like receptors: triggers of regulated cell death and promising targets for cancer therapy. Immunol Lett. 2020;223:1-9.

2. Miyake M, Ohnishi K, Hori S, Nakano A, Nakano R, Yano H, Ohnishi S, Owari T, Morizawa Y, Itami Y, Nakai Y, Inoue T, Anai S, Torimoto K, Tanaka N, Fujii T, Furuya H, Rosser CJ, Fujimoto K. Mycoplasma genitalium infection and chronic inflammation in human prostate cancer: detection using prostatectomy and needle biopsy specimens. Cells. 2019;8:212.

3. Hemmat N, Bannazadeh Baghi H. Association of human papillomavirus infection and inflammation in cervical cancer. Pathog Dis. 2019;77:ftz048.

4. Zha L, Garrett S, Sun J. salmonella infection in chronic inflammation and gastrointestinal cancer. Diseases. 2019;7:28.

5. Cox M, Kartikasari AER, Gorry PR, Flanagan KL, Plebanski M. Potential impact of human cytomegalovirus infection on immunity to ovarian tumours and cancer progression. Biomedicines. 2021:9:351.

6. Yang YM, Kim SY, Seki E. Inflammation and liver cancer: molecular mechanisms and therapeutic targets. Semin Liver Dis. 2019;39:26-42.

7. Yao D, Dong M, Dai C, Wu S. Inflammation and inflammatory cytokine contribute to the initiation and development of ulcerative colitis and its associated cancer. Inflamm Bowel Dis. 2019;25:1595-602.

8. Ranjbar M, Salehi R, Haghjooy Javanmard S, Rafiee L, Faraji H, Jafarpor S, Ferns GA, Ghayour-Mobarhan M, Manian M, Nedaeinia R. The dysbiosis signature of Fusobacterium nucleatum in colorectal cancer-cause or consequences? A systematic review. Cancer Cell Int. 2021:21:194.

9. Kraus S, Arber N. Inflammation and colorectal cancer. Curr Opin Pharmacol. 2009;9:405-10.

10. Chen J, Pitmon E, Wang K. Microbiome, inflammation and colorectal cancer. Semin Immunol. 2017:32:43-53.

11. Fantini MC, Guadagni I. From inflammation to colitis-associated colorectal cancer in inflammatory bowel disease: pathogenesis and impact of current therapies. Dig Liver Dis. 2021;S1590-8658(21):00018-9.

12. Herrinton LJ, Liu L, Levin TR, Allison JE, Lewis JD, Velayos F. Incidence and mortality of colorectal adenocarcinoma in persons with inflammatory bowel disease from 1998 to 2010. Gastroenterology. 2012:143:382-9.

13. Lakatos PL, Lakatos L. Risk for colorectal cancer in ulcerative colitis: changes, causes and management strategies. World J Gastroenterol. 2008;14:3937-47.

14. Yu MR, Kim HJ, Park HR. Fusobacterium nucleatum accelerates the progression of colitis-associated colorectal cancer by promoting EMT. Cancers. 2020;12:2728.

15. Mokhtari Y, Pourbagheri-Sigaroodi A, Zafari P, Bagheri N, Ghaffari $\mathrm{SH}$, Bashash D. Toll-like receptors (TLRs): an old family of immune receptors with a new face in cancer pathogenesis. J Cell Mol Med. 2021;25:639-51.

16. Kashani B, Zandi Z, Pourbagheri-Sigaroodi A, Bashash D, Ghaffari SH. The role of toll-like receptor 4 (TLR4) in cancer progression: A possible therapeutic target? J Cell Physiol. 2021;236:4121-37.

17. Sheikh A, Taube J, Greathouse KL. Contribution of the microbiota and their secretory products to inflammation and colorectal cancer pathogenesis: the role of toll-like receptors. Carcinogenesis. 2021. https://doi. org/10.1093/carcin/bgab06.

18. McCall KD, Muccioli M, Benencia F. Toll-like receptors signaling in the tumor microenvironment. Adv Exp Med Biol. 2020;1223:81-97.

19. Pimentel-Nunes P, Gonçalves N, Boal-Carvalho I, Afonso L, Lopes P, Roncon-Albuquerque R Jr, Henrique R, Moreira-Dias L, Leite-Moreira AF, Dinis-Ribeiro M. Helicobacter pylori induces increased expression of toll-like receptors and decreased toll-interacting protein in gastric mucosa that persists throughout gastric carcinogenesis. Helicobacter 2013;18:22-32.

20. Hong EH, Cho J, Ahn JH, Kwon BE, Kweon MN, Seo SU, Yoon BI, Chang SY, Ko HJ. Plasmacytoid dendritic cells regulate colitis-associated tumorigenesis by controlling myeloid-derived suppressor cell infiltration. Cancer Lett. 2020;493:102-12. 
21. Grimmig T, Matthes N, Hoeland K, Tripathi S, Chandraker A, Grimm M, Moench R, Moll EM, Friess H, Tsaur I, Blaheta RA, Germer CT, WaagaGasser AM, Gasser M. TLR7 and TLR8 expression increases tumor cell proliferation and promotes chemoresistance in human pancreatic cancer. Int J Oncol. 2015:47:857-66.

22. Ochi A, Graffeo CS, Zambirinis CP, Rehman A, Hackman M, Fallon N, Barilla RM, Henning JR, Jamal M, Rao R, Greco S, Deutsch M, Medina-Zea MV, Bin Saeed U, Ego-Osuala MO, Hajdu C, Miller G. Toll-like receptor 7 regulates pancreatic carcinogenesis in mice and humans. J Clin Invest. 2012;122:4118-29.

23. Fukata M, Shang L, Santaolalla R, Sotolongo J, Pastorini C, España C, Ungaro R, Harpaz N, Cooper HS, Elson G, Kosco-Villbois M, Zaias J, Perez MT, Mayer L, Vamadevan AS, Lira SA, Abreu MT. Constitutive activation of epithelial TLR4 augments inflammatory responses to mucosal injury and drives colitis-associated tumorigenesis. Inflamm Bowel Dis. 2011;17:1464-73.

24. Fukata M, Hernandez Y, Conduah D, Cohen J, Chen A, Breglio K, Goo T, Hsu D, Xu R, Abreu MT. Innate immune signaling by Toll-like receptor-4 (TLR4) shapes the inflammatory microenvironment in colitis-associated tumors. Inflamm Bowel Dis. 2009:15:997-1006.

25. Akira S. Innate immunity and adjuvants. Philos Trans R Soc Lond B Biol Sci. 2011;366:2748-55.

26. Hernandez Y, Sotolongo J, Fukata M. Toll-like receptor 4 signaling integrates intestinal inflammation with tumorigenesis: lessons from the murine model of colitis-associated cancer. Cancers (Basel). 2011;3:3104-13.

27. Garcia MM, Goicoechea C, Molina-Alvarez M, Pascual D. Toll-like receptor 4: a promising crossroads in the diagnosis and treatment of several pathologies. Eur J Pharmacol. 2020;874:172975.

28. Liu L, Li YH, Niu YB, Sun Y, Guo ZJ, Li Q, Li C, Feng J, Cao SS, Mei QB. An apple oligogalactan prevents against inflammation and carcinogenesis by targeting LPS/TLR4/NF-kappaB pathway in a mouse model of colitisassociated colon cancer. Carcinogenesis. 2010;31:1822-32.

29. Yu T, Guo F, Yu Y, Sun T, Ma D, Han J, Qian Y, Kryczek I, Sun D, Nagarsheth $\mathrm{N}$, Chen Y, Chen H, Hong J, Zou W, Fang JY. Fusobacterium nucleatum promotes chemoresistance to colorectal cancer by modulating autophagy. Cell. 2017;170:548-63.e16.

30. LiTT, Ogino S, Qian ZR. Toll-like receptor signaling in colorectal cancer: carcinogenesis to cancer therapy. World J Gastroenterol. 2014:20:17699-708.

31. Pandey N, Chauhan A, Jain N. TLR4 polymorphisms and expression in solid cancers. Mol Diagn Ther. 2018;22:683-702.

32. Mishra V, Pathak C. Human toll-like receptor 4 (hTLR4): structural and functional dynamics in cancer. Int J Biol Macromol. 2019;122:425-51.

33. Kamba A, Lee IA, Mizoguchi E. Potential association between TLR4 and chitinase 3-like 1 (CHI3L1/YKL-40) signaling on colonic epithelial cells in inflammatory bowel disease and colitis-associated cancer. Curr Mol Med. 2013;13:1110-21.

34. Lv Z, Wang Z, Luo L, Chen Y, Han G, Wang R, Xiao H, Li X, Hou C, Feng J, Shen B, Wang Y, Peng H, Guo R, Li Y, Chen G. Spliceosome protein Eftud2 promotes colitis-associated tumorigenesis by modulating inflammatory response of macrophage. Mucosal Immunol. 2019:12:1164-73.

35. Inoue R, Yajima T, Tsukahara T. Expression of TLR2 and TLR4 in murine small intestine during postnatal development. Biosci Biotechnol Biochem. 2017:81:350-8.

36. Dejban P, Nikravangolsefid N, Chamanara M, Dehpour A, Rashidian A. The role of medicinal products in the treatment of inflammatory bowel diseases (IBD) through inhibition of TLR4/NF-kappaB pathway. Phytother Res. 2021;35:835-45.

37. Brown M, Hughes KR, Moossavi S, Robins A, Mahida YR. Toll-like receptor expression in crypt epithelial cells, putative stem cells and intestinal myofibroblasts isolated from controls and patients with inflammatory bowel disease. Clin Exp Immunol. 2014;178:28-39.

38. Tan Y, Zou KF, Qian W, Chen S, Hou XH. Expression and implication of toll-like receptors TLR2, TLR4 and TLR9 in colonic mucosa of patients with ulcerative colitis. J Huazhong Univ Sci Technol Med Sci. 2014;34:785-90.

39. Fernandes P, MacSharry J, Darby T, Fanning A, Shanahan F, Houston A, Brint E. Differential expression of key regulators of Toll-like receptors in ulcerative colitis and Crohn's disease: A role for Tollip and peroxisome proliferator-activated receptor gamma? Clin Exp Immunol. 2016;183:358-68.

40. Rafa H, Benkhelifa S, AitYounes S, Saoula H, Belhadef S, Belkhelfa M, Boukercha A, Toumi R, Soufli I, Moralès O, de Launoit Y, Mahfouf H, Nakmouche M, Delhem N, Touil-Boukoffa C. All-trans retinoic acid modulates TLR4/NF-KB signaling pathway targeting TNF-a and nitric oxide synthase 2 expression in colonic mucosa during ulcerative colitis and colitis associated cancer. Mediat Inflamm. 2017;2017:7353252.

41. Li XX, Sun GP, Meng J, Li X, Tang YX, Li Z, Wang MF, Liang GF, Lu XB. Role of toll-like receptor 4 in colorectal carcinogenesis: a meta-analysis. PLoS ONE. 2014;9:e93904.

42. Sussman DA, Santaolalla R, Bejarano PA, Garcia-Buitrago MT, Perez MT, Abreu MT, Clarke J. In silico and Ex vivo approaches identify a role for toll-like receptor 4 in colorectal cancer. J Exp Clin Cancer Res. 2014;33:45

43. Fukata M, Chen A, Vamadevan AS, Cohen J, Breglio K, Krishnareddy S, Hsu D, Xu R, Harpaz N, Dannenberg AJ, Subbaramaiah K, Cooper HS, Itzkowitz SH, Abreu MT. Toll-like receptor-4 promotes the development of colitis-associated colorectal tumors. Gastroenterology. 2007:133:1869-81.

44. Makkar S, Riehl TE, Chen B, Yan Y, Alvarado DM, Ciorba MA, Stenson WF. Hyaluronic acid binding to TLR4 promotes proliferation and blocks apoptosis in colon cancer. Mol Cancer Ther. 2019;18:2446-56.

45. Shi YJ, Zhao QQ, Liu XS, Dong SH, Ji-Fu EF, Li X, Liu C, Wang H. Toll-like receptor 4 regulates spontaneous intestinal tumorigenesis by upregulating IL-6 and GM-CSF. J Cell Mol Med. 2020;24:385-97.

46. Shi YJ, Gong HF, Zhao QQ, Liu XS, Liu C, Wang H. Critical role of toll-like receptor 4 (TLR4) in dextran sulfate sodium (DSS)-induced intestinal injury and repair. Toxicol Lett. 2019;315:23-30.

47. Santaolalla R, Sussman DA, Ruiz JR, Davies JM, Pastorini C, España CL, Sotolongo J, Burlingame O, Bejarano PA, Philip S, Ahmed MM, Ko J, Dirisina R, Barrett TA, Shang L, Lira SA, Fukata M, Abreu MT. TLR4 activates the beta-catenin pathway to cause intestinal neoplasia. PLoS ONE. 2013;8:e63298.

48. Ye K, Wu Y, Sun Y, Lin J, Xu J. TLR4 siRNA inhibits proliferation and invasion in colorectal cancer cells by downregulating ACAT1 expression. Life Sci. 2016;155:133-9.

49. Kuo WT, Lee TC, Yu LC. Eritoran suppresses colon cancer by altering a functional balance in toll-like receptors that bind lipopolysaccharide. Cancer Res. 2016;76:4684-95.

50. Wu Y, Wu J, Chen T, Li Q, Peng W, Li H, Tang X, Fu X. Fusobacterium nucleatum potentiates intestinal tumorigenesis in mice via a toll-like receptor 4/p21-activated kinase 1 cascade. Dig Dis Sci. 2018;63:1210-8.

51. Fukata M, Chen A, Klepper A, Krishnareddy S, Vamadevan AS, Thomas $L S$, Xu R, Inoue H, Arditi M, Dannenberg AJ, Abreu MT. Cox-2 is regulated by toll-like receptor-4 (TLR4) signaling: role in proliferation and apoptosis in the intestine. Gastroenterology. 2006;131:862-77.

52. Shi YJ, Hu SJ, Zhao QQ, Liu XS, Liu C, Wang H. Toll-like receptor 4 (TLR4) deficiency aggravates dextran sulfate sodium (DSS)-induced intestinal injury by down-regulating IL6, CCL2 and CSF3. Ann Transl Med. 2019;7:713.

53. Tang $X$, Zhu Y. TLR4 signaling promotes immune escape of human colon cancer cells by inducing immunosuppressive cytokines and apoptosis resistance. Oncol Res. 2012;20:15-24.

54. Chung YH, Kim D. Enhanced TLR4 expression on colon cancer cells after chemotherapy promotes cell survival and epithelial-mesenchymal transition through phosphorylation of GSK3 3 . Anticancer Res. 2016;36:3383-94.

55. Kuo WT, Lee TC, Yang HY, Chen CY, Au YC, Lu YZ, Wu LL, Wei SC, Ni YH, Lin BR, Chen Y, Tsai YH, Kung JT, Sheu F, Lin LW, Yu LC. LPS receptor subunits have antagonistic roles in epithelial apoptosis and colonic carcinogenesis. Cell Death Differ. 2015;22:1590-604.

56. Li Y, Teo WL, Low MJ, Meijer L, Sanderson I, Pettersson S, Greicius G. Constitutive TLR4 signalling in intestinal epithelium reduces tumor load by increasing apoptosis in APC(Min/+) mice. Oncogene. 2014;33:369-77.

57. Wang EL, Qian ZR, Nakasono M, Tanahashi T, Yoshimoto K, Bando Y, Kudo E, Shimada M, Sano T. High expression of Toll-like receptor 4/ myeloid differentiation factor 88 signals correlates with poor prognosis in colorectal cancer. Br J Cancer. 2010;102:908-15. 
58. Ying J, Zhou HY, Liu P, You Q, Kuang F, Shen YN, Hu ZQ. Aspirin inhibited the metastasis of colon cancer cells by inhibiting the expression of tolllike receptor 4. Cell Biosci. 2018;8:1.

59. Chruścik A, Gopalan V, Lam AK. The clinical and biological roles of transforming growth factor beta in colon cancer stem cells: a systematic review. Eur J Cell Biol. 2018;97:15-22.

60. Killeen SD, Wang JH, Andrews EJ, Redmond HP. Bacterial endotoxin enhances colorectal cancer cell adhesion and invasion through TLR-4 and NF-kappaB-dependent activation of the urokinase plasminogen activator system. Br J Cancer. 2009;100:1589-602.

61. Nagano M, Hoshino D, Koshikawa N, Akizawa T, Seiki M. Turnover of focal adhesions and cancer cell migration. Int J Cell Biol. 2012:2012:310616.

62. Hsu RY, Chan CH, Spicer JD, Rousseau MC, Giannias B, Rousseau S, Ferri LE. LPS-induced TLR4 signaling in human colorectal cancer cells increases beta1 integrin-mediated cell adhesion and liver metastasis. Cancer Res. 2011;71:1989-98.

63. Rajamanickam V, Yan T, Xu S, Hui J, Xu X, Ren L, Liu Z, Liang G, Wang O, Wang Y. Selective targeting of the TLR4 co-receptor, MD2, prevents colon cancer growth and lung metastasis. Int J Biol Sci. 2020;16:1288-302.

64. Ridge SM, Sullivan FJ, Glynn SA. Mesenchymal stem cells: key players in cancer progression. Mol Cancer. 2017;16:31.

65. Cammarota R, Bertolini V, Pennesi G, Bucci EO, Gottardi O, Garlanda C, Laghi L, Barberis MC, Sessa F, Noonan DM, Albini A. The tumor microenvironment of colorectal cancer: stromal TLR-4 expression as a potential prognostic marker. J Transl Med. 2010;8:112.

66. Ungaro R, Fukata M, Hsu D, Hernandez Y, Breglio K, Chen A, Xu R, Sotolongo J, Espana C, Zaias J, Elson G, Mayer L, Kosco-Vilbois M, Abreu MT. A novel Toll-like receptor 4 antagonist antibody ameliorates inflammation but impairs mucosal healing in murine colitis. Am J Physiol Gastrointest Liver Physiol. 2009;296:G1 167-79.

67. Sica A, Mantovani A. Macrophage plasticity and polarization: in vivo veritas. J Clin Investog. 2012;122:787-95.

68. Chen T, Li Q, Wu J, Wu Y, Peng W, Li H, Wang J, Tang X, Peng Y, Fu X. Fusobacterium nucleatum promotes $M 2$ polarization of macrophages in the microenvironment of colorectal tumours via a TLR4-dependent mechanism. Cancer Immunol Immunother. 2018:67:1635-46.

69. Yesudhas D, Gosu V, Anwar MA, Choi S. Multiple roles of toll-like receptor 4 in colorectal cancer. Front Immunol. 2014;5:334.

70. Quinn EM, Wang J, Redmond HP. The emerging role of microRNA in regulation of endotoxin tolerance. J Leukoc Biol. 2012;91:721-7.

71. Litak J, Grochowski C, Litak J, Osuchowska I, Gosik K, Radzikowska E, Kamieniak P, Rolinski J. TLR-4 signaling vs. immune checkpoints, miRNAs molecules, cancer stem cells, and wingless-signaling interplay in glioblastoma multiforme-future perspectives. Int J Mol Sci. 2020;21:3114.

72. Josse C, Bours V. MicroRNAs and inflammation in colorectal cancer. Adv Exp Med Biol. 2016;937:53-69.

73. Nahid MA, Satoh M, Chan EK. MicroRNA in TLR signaling and endotoxin tolerance. Cell Mol Immunol. 2011;8:388-403.

74. Zhang L, Fan XM. The pathological role of microRNAs and inflammation in colon carcinogenesis. Clin Res Hepatol Gastroenterol. 2015;39:174-9.

75. Min M, Peng L, Yang Y, Guo M, Wang W, Sun G. MicroRNA-155 is involved in the pathogenesis of ulcerative colitis by targeting $\mathrm{FOXO3a.}$ Inflamm Bowel Dis. 2014:20:652-9.

76. Valmiki S, Ahuja V, Paul J. MicroRNA exhibit altered expression in the inflamed colonic mucosa of ulcerative colitis patients. World J Gastroenterol. 2017:23:5324-32.

77. Gwiggner M, Martinez-Nunez RT, Whiteoak SR, Bondanese VP, Claridge A, Collins JE, Cummings JRF, Sanchez-Elsner T. MicroRNA-31 and microRNA-155 are overexpressed in ulcerative colitis and regulate IL-13 signaling by targeting interleukin 13 receptor a-1. Genes. 2018;9:85.

78. Liu Y, Zhu F, Li H, Fan H, Wu H, Dong Y, Chu S, Tan C, Wang Q, He H, Gao F, Leng X, Zhou Q, Zhu X. MiR-155 contributes to intestinal barrier dysfunction in DSS-induced mice colitis via targeting HIF-1a/TFF-3 axis. Aging. 2020;12:14966-77.
79. El-Daly SM, Omara EA, Hussein J, Youness ER, El-Khayat Z. Differential expression of miRNAs regulating NF-KB and STAT3 crosstalk during colitis-associated tumorigenesis. Mol Cell Probes. 2019;47:101442.

80. Lu ZJ, Wu JJ, Jiang WL, Xiao JH, Tao KZ, Ma L, Zheng P, Wan R, Wang XP. MicroRNA-155 promotes the pathogenesis of experimental colitis by repressing SHIP-1 expression. World J Gastroenterol. 2017;23:976-85.

81. Zhu F, Li H, Liu Y, Tan C, Liu X, Fan H, Wu H, Dong Y, Yu T, Chu S, He H, Zhu X. miR-155 antagomir protect against DSS-induced colitis in mice through regulating Th17/Treg cell balance by Jarid2/Wnt/B-catenin. Biomed Pharmacother. 2020;126:109909.

82. Chen S, Wang L, Fan J, Ye C, Dominguez D, Zhang Y, Curiel TJ, Fang D, Kuzel TM, Zhang B. Host miR155 promotes tumor growth through a myeloid-derived suppressor cell-dependent mechanism. Cancer Res. 2015;75:519-31.

83. Tili E, Michaille JJ, Wernicke D, Alder H, Costinean S, Volinia S, Croce CM. Mutator activity induced by microRNA-155 (miR-155) links inflammation and cancer. Proc Natl Acad Sci USA. 2011;108:4908-13.

84. Yu H, Xu W, Gong F, Chi B, Chen J, Zhou L. MicroRNA-155 regulates the proliferation, cell cycle, apoptosis and migration of colon cancer cells and targets CBL. Exp Ther Med. 2017:14:4053-60.

85. Onyeagucha BC, Mercado-Pimentel ME, Hutchison J, Flemington EK, Nelson MA. S100P/RAGE signaling regulates microRNA-155 expression via AP-1 activation in colon cancer. Exp Cell Res. 2013;319:2081-90.

86. Velázquez KT, Enos RT, McClellan JL, Cranford TL, Chatzistamou I, Singh UP, Nagarkatti M, Nagarkatti PS, Fan D, Murphy EA. MicroRNA-155 deletion promotes tumorigenesis in the azoxymethane-dextran sulfate sodium model of colon cancer. Am J Physiol Gastrointest Liver Physiol. 2016;310:G347-58.

87. Vigorito E, Kohlhaas S, Lu D, Leyland R. miR-155: an ancient regulator of the immune system. Immunol Rev. 2013;253:146-57.

88. Quinn SR, O'Neill LA. A trio of microRNAs that control Toll-like receptor signalling. Int Immunol. 2011;23:421-5.

89. Marques-Rocha JL, Garcia-Lacarte M, Samblas M, Bressan J, Martinez JA, Milagro Fl. Regulatory roles of miR-155 and let-7b on the expression of inflammation-related genes in THP-1 cells: effects of fatty acids. J Physiol Biochem. 2018;74:579-89.

90. Luo Q, Zeng J, LiW, Lin L, Zhou X, Tian X, Liu W, Zhang L, Zhang X. Silencing of miR-155 suppresses inflammatory responses in psoriasis through inflammasome NLRP3 regulation. Int J Mol Med. 2018;42:1086-95.

91. Fu X, He HD, Li CJ, Li N, Jiang SY, Ge HW, Wang R, Wang XL. MicroRNA-155 deficiency attenuates inflammation and oxidative stress in experimental autoimmune prostatitis in a TLR4-dependent manner. Kaohsiung J Med Sci. 2020;36:712-20.

92. Wen Y, Zhang X, Dong L, Zhao J, Zhang C, Zhu C. Acetylbritannilactone modulates microRNA-155-mediated inflammatory response in ischemic cerebral tissues. Mol Med. 2015;21:197-209.

93. Chen Y, Liu W, Sun T, Huang Y, Wang Y, Deb DK, Yoon D, Kong J, Thadhani $R$, Li YC. 1,25-Dihydroxyvitamin D promotes negative feedback regulation of TLR signaling via targeting microRNA-155-SOCS1 in macrophages. J Immunol. 2013;190:3687-95.

94. Wang Z, Filgueiras LR, Wang S, Serezani AP, Peters-Golden M, Jancar S, Serezani $\mathrm{CH}$. Leukotriene B4 enhances the generation of proinflammatory microRNAs to promote MyD88-dependent macrophage activation. J Immunol. 2014;192:2349-56.

95. Kempinska-Podhorodecka A, Milkiewicz M, Wasik U, Ligocka J, Zawadzki M, Krawczyk M, Milkiewicz P. Decreased expression of vitamin D receptor affects an immune response in primary biliary cholangitis via the VDR-miRNA155-SOCS1 pathway. Int J Mol Sci. 2017;18:289.

96. Wang R, Leong RW. Primary sclerosing cholangitis as an independent risk factor for colorectal cancer in the context of inflammatory bowel disease: a review of the literature. World J Gastroenterol. 2014;20:8783-9.

97. Boonstra K, Weersma RK, van Erpecum KJ, Rauws EA, Spanier BW, Poen AC, van Nieuwkerk KM, Drenth JP, Witteman BJ, Tuynman HA, Naber $A H$, Kingma PJ, van Buuren HR, van Hoek B, Vleggaar FP, van Geloven N, Beuers U, Ponsioen CY, EpiPSCPBC Study Group. Population-based 
epidemiology, malignancy risk, and outcome of primary sclerosing cholangitis. Hepatology. 2013;58:2045-55.

98. Mueller T, Beutler C, Picó AH, Shibolet O, Pratt DS, Pascher A, Neuhaus P, Wiedenmann B, Berg T, Podolsky DK. Enhanced innate immune responsiveness and intolerance to intestinal endotoxins in human biliary epithelial cells contributes to chronic cholangitis. Liver Int. 2011:31:1574-88.

99. Dhillon AK, Kummen M, Trøseid M, Åkra S, Liaskou E, Moum B, Vesterhus M, Karlsen TH, Seljeflot I, Hov JR. Circulating markers of gut barrier function associated with disease severity in primary sclerosing cholangitis. Liver Int. 2019;39:371-81.

100. Bala S, Csak T, Kodys K, Catalano D, Ambade A, Furi I, Lowe P, Cho Y, Iracheta-Vellve A, Szabo G. Alcohol-induced miR-155 and HDAC11 inhibit negative regulators of the TLR4 pathway and lead to increased LPS responsiveness of Kupffer cells in alcoholic liver disease. J Leukoc Biol. 2017;102:487-98.

101. Feng Y, Zheng C, Zhang Y, Xing C, Cai W, Li R, Chen J, Duan Y. Triptolide inhibits preformed fibril-induced microglial activation by targeting the microRNA155-5p/SHIP1 pathway. Oxid Med Cell Longev. 2019:2019:6527638.

102. An H, Xu H, Zhang M, Zhou J, Feng T, Qian C, Qi R, Cao X. Src homology 2 domain-containing inositol-5-phosphatase 1 (SHIP1) negatively regulates TLR4-mediated LPS response primarily through a phosphatase activity- and PI-3K-independent mechanism. Blood. 2005;105:4685-92.

103. Tili $E_{\text {, Croce } C M}$, Michaille JJ. miR-155: on the crosstalk between inflammation and cancer. Int Rev Immunol. 2009;28:264-84.

104. O'Neill LA, Sheedy FJ, McCoy CE. MicroRNAs: the fine-tuners of Toll-like receptor signalling. Nat Rev Immunol. 2011;11:163-75.

105. Schulte LN, Westermann AJ, Vogel J. Differential activation and functional specialization of miR-146 and miR-155 in innate immune sensing. Nucleic Acids Res. 2013:41:542-53.

106. Sun Y, Cai J, Ma F, Lu P, Huang H, Zhou J. miR-155 mediates suppressive effect of progesterone on TLR3, TLR4-triggered immune response. Immunol Lett. 2012;146:25-30.

107. Terrazas LI, Sánchez-Muñoz F, Pérez-Miranda M, Mejía-Domínguez AM, Ledesma-Soto Y, Bojalil R, Gómez-García L. Helminth excreted/ secreted antigens repress expression of LPS-induced Let-7i but not miR-146a and miR-155 in human dendritic cells. Biomed Res Int. 2013;2013:972506.

108. Bros M, Youns M, Kollek V, Buchmüller D, Bollmann F, Seo EJ, Schupp J, Montermann E, Usanova S, Kleinert H, Efferth T, Reske-Kunz AB. Differentially tolerized mouse antigen presenting cells share a common miRNA signature including enhanced mmu-miR-223-3p expression which is sufficient to imprint a protolerogenic state. Front Pharmacol. 2018;9:915.

109. Lu D, Yamawaki T, Zhou H, Chou WY, Chhoa M, Lamas E, Escobar SS, Arnett HA, Ge H, Juan T, Wang S, Li CM. Limited differential expression of miRNAs and other small RNAs in LPS-stimulated human monocytes. PLoS ONE. 2019;14:2e0214296.

110. Quinn SR, Mangan NE, Caffrey BE, Gantier MP, Williams BR, Hertzog PJ, McCoy CE, O'Neill LA. The role of Ets2 transcription factor in the induction of microRNA-155 (miR-155) by lipopolysaccharide and its targeting by interleukin-10. J Biol Chem. 2014:289:4316-25.

111. Cardoso AL, Guedes JR, Pereira de Almeida L, Pedroso de Lima MC. miR-155 modulates microglia-mediated immune response by downregulating SOCS-1 and promoting cytokine and nitric oxide production. Immunology. 2012;135:73-88.

112. Juknat A, Gao F, Coppola G, Vogel Z, Kozela E. miRNA expression profiles and molecular networks in resting and LPS-activated BV-2 microgliaeffect of cannabinoids. PLOS ONE. 2019;14:e0212039.

113. Abulwerdi G, Stoica BA, Loane DJ, Faden Al. Putative mGluR4 positive allosteric modulators activate Gi-independent anti-inflammatory mechanisms in microglia. Neurochem Int. 2020;138:104770.

114. Lu S, Dong L, Jing X, Gen-Yang C, Zhan-Zheng Z. Abnormal IncRNA CCAT1/microRNA-155/SIRT1 axis promoted inflammatory response and apoptosis of tubular epithelial cells in LPS caused acute kidney injury. Mitochondrion. 2020;53:76-90.
115. Du J, Jiang S, Hu Z, Tang S, Sun Y, He J, Li Z, Yi B, Wang J, Zhang H, Li YC. Vitamin $D$ receptor activation protects against lipopolysaccharideinduced acute kidney injury through suppression of tubular cell apoptosis. Am J Physiol Renal Physiol. 2019;316:F1068-77.

116. Li H, Liu P, Gong Y, Liu J, Ruan F. Expression and function of miR-155 in rat synovial fibroblast model of rheumatoid arthritis. Exp Ther Med. 2019;18:786-92.

117. Jing C, Guo M, Bao X, Li T, Lin J, Lu X, Wang W. Pitavastatin up-regulates eNOS production by suppressing miR-155 expression in lipopolysaccharide-stimulated human umbilical vein endothelial cells. Cardiovasc Ther. 2017;35:e12282.

118. Sul OJ, Sung YB, Rajasekaran M, Ke K, Yu R, Back SH, Choi HS. MicroRNA-155 induces autophagy in osteoclasts by targeting transforming growth factor $\beta$-activated kinase 1-binding protein 2 upon lipopolysaccharide stimulation. Bone. 2018;116:279-89.

119. Huang Y, Jia Z, Xu Y, Qin M, Feng S. Selenium protects against LPS-induced MC3T3-E1 cells apoptosis through modulation of microRNA-155 and PI3K/Akt signaling pathways. Genet Mol Biol. 2020;43:e20190153.

120. Jiang S, Zhang HW, Lu MH, He XH, Li Y, Gu H, Liu MF, Wang ED. MicroRNA-155 functions as an OncomiR in breast cancer by targeting the suppressor of cytokine signaling 1 gene. Cancer Res. 2010;70:3119-27.

121. Thompson RC, Herscovitch M, Zhao I, Ford TJ, Gilmore TD. NF-kappaB down-regulates expression of the B-lymphoma marker CD10 through a miR-155/PU.1 pathway. J Biol Chem. 2011;286:1675-82.

122. Zhu M, Wei Y, Geißler C, Abschlag K, Corbalán Campos J, Hristov M, Möllmann J, Lehrke M, Karshovska E, Schober A. Hyperlipidemiainduced MicroRNA-155-5p improves $\beta$-cell function by targeting Mafb. Diabetes. 2017;66:3072-84.

123. De Santis R, Liepelt A, Mossanen JC, Dueck A, Simons N, Mohs A, Trautwein C, Meister G, Marx G, Ostareck-Lederer A, Ostareck DH. miR-155 targets Caspase-3 mRNA in activated macrophages. RNA Biol. 2016;13:43-58.

124. Liu C, Du X, Zhou X, Kolosov VP, Perelman JM. MicroRNA-155 regulates lipopolysaccharide-induced mucin 5 AC overproduction via a suppressor of cytokine signaling 1-mediated mechanism in human bronchial epithelial cells. Respir Physiol Neurobiol. 2019;264:12-8.

125. Sayed AS, Gomaa IEO, Bader M, El Sayed NSED. Role of 3-acetyl-1 1-ketobeta-boswellic acid in counteracting LPS-induced neuroinflammation via modulation of miRNA-155. Mol Neurobiol. 2018;55:5798-808.

126. Yang ZB, Chen WW, Chen HP, Cai SX, Lin JD, Qiu LZ. MiR-155 aggravated septic liver injury by oxidative stress-mediated ER stress and mitochondrial dysfunction via targeting Nrf-2. Exp Mol Pathol. 2018;105:387-94.

127. Wang H, Bei Y, Huang $\mathrm{P}$, Zhou Q, Shi J, Sun Q, Zhong J, Li X, Kong X, Xiao J. Inhibition of miR-155 protects against LPS-induced cardiac dysfunction and apoptosis in mice. Mol Ther Nucleic Acids. 2016;5:374.

128. Wang W, Liu Z, Su J, Chen WS, Wang XW, Bai SX, Zhang JZ, Yu SQ. Macrophage micro-RNA-155 promotes lipopolysaccharide-induced acute lung injury in mice and rats. Am J Physiol Lung Cell Mol Physiol. 2016;311:L494-506.

129. Zhao X, Wang X, Wang F, Gao C, Wang J. Poly r(C) binding protein 1-mediated regulation of microRNA expression underlies postsevoflurane amelioration of acute lung injury in rats. J Cell Physiol. 2018;233:3048-54.

130. Bala S, Csak T, Saha B, Zatsiorsky J, Kodys K, Catalano D, Satishchandran A, Szabo G. The pro-inflammatory effects of miR-155 promote liver fibrosis and alcohol-induced steatohepatitis. J Hepatol. 2016;64:1378-87.

131. Pathak S, Grillo AR, Scarpa M, Brun P, D'Incà R, Nai L, Banerjee A, Cavallo D, Barzon L, Palù G, Sturniolo GC, Buda A, Castagliuolo I. MiR-155 modulates the inflammatory phenotype of intestinal myofibroblasts by targeting SOCS1 in ulcerative colitis. Exp Mol Med. 2015;47:e164.

132. Arboleda JF, Fernandez GJ, Urcuqui-Inchima S. Vitamin D-mediated attenuation of miR-155 in human macrophages infected with dengue virus: implications for the cytokine response. Infect Genet Evol. 2019:69:12-21.

133. Bala S, Marcos M, Kodys K, Csak T, Catalano D, Mandrekar P, Szabo G. Upregulation of microRNA-155 in macrophages contributes to increased 
tumor necrosis factor alpha (TNF \{alpha\}) production via increased mRNA half-life in alcoholic liver disease. J Biol Chem. 2011;286:1436-44.

134. Dai Y, Diao Z, Sun H, Li R, Qiu Z, Hu Y. MicroRNA-155 is involved in the remodelling of human-trophoblast-derived HTR-8/SVneo cells induced by lipopolysaccharides. Hum Reprod. 2011;26:1882-91.

135. McCoy CE, Sheedy FJ, Qualls JE, Doyle SL, Quinn SR, Murray PJ, O'Neill LA. IL-10 inhibits miR-155 induction by toll-like receptors. J Biol Chem. 2010;285:20492-8.

136. Ruggiero T, Trabucchi M, De Santa F, Zupo S, Harfe BD, McManus MT, Rosenfeld MG, Briata P, Gherzi R. LPS induces KH-type splicing regulatory protein-dependent processing of microRNA-155 precursors in macrophages. FASEB J. 2009;23:2898-908.

137. He X, Jing Z, Cheng G. MicroRNAs: new regulators of Toll-like receptor signalling pathways. Biomed Res Int. 2014;2014:945169.

138. Tili E, Michaille JJ, Croce CM. MicroRNAs play a central role in molecular dysfunctions linking inflammation with cancer. Immunol Rev. 2013;253:167-84.
139. Shi C, Yang Y, Xia Y, Okugawa Y, Yang J, Liang Y, Chen H, Zhang P, Wang F, Han H, Wu W, Gao R, Gasche C, Qin H, Ma Y, Goel A. Novel evidence for an oncogenic role of microRNA-21 in colitis-associated colorectal cancer. Gut. 2016;65:1470-81.

140. Iliopoulos D, Jaeger SA, Hirsch HA, Bulyk ML, Struhl K. STAT3 activation of miR-21 and miR-181 b-1 via PTEN and CYLD are part of the epigenetic switch linking inflammation to cancer. Mol Cell. 2010;39:493-506.

\section{Publisher's Note}

Springer Nature remains neutral with regard to jurisdictional claims in published maps and institutional affiliations.
Ready to submit your research? Choose BMC and benefit from:

- fast, convenient online submission

- thorough peer review by experienced researchers in your field

- rapid publication on acceptance

- support for research data, including large and complex data types

- gold Open Access which fosters wider collaboration and increased citations

- maximum visibility for your research: over $100 \mathrm{M}$ website views per year

At BMC, research is always in progress.

Learn more biomedcentral.com/submissions 